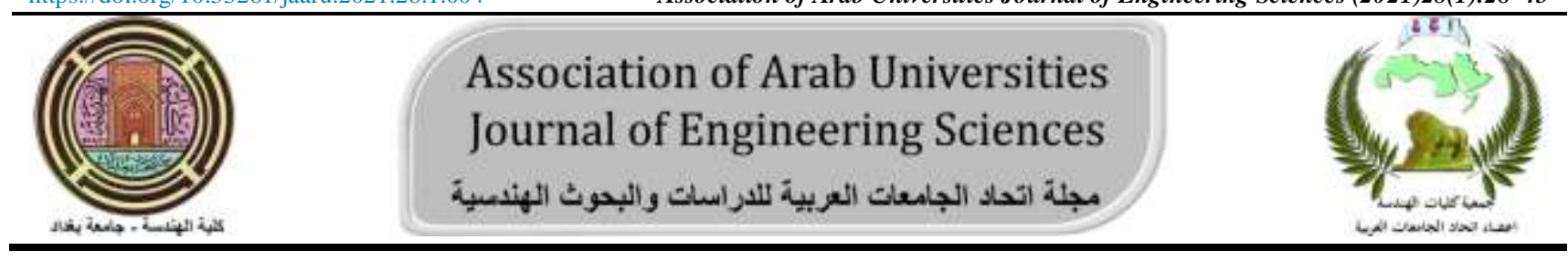

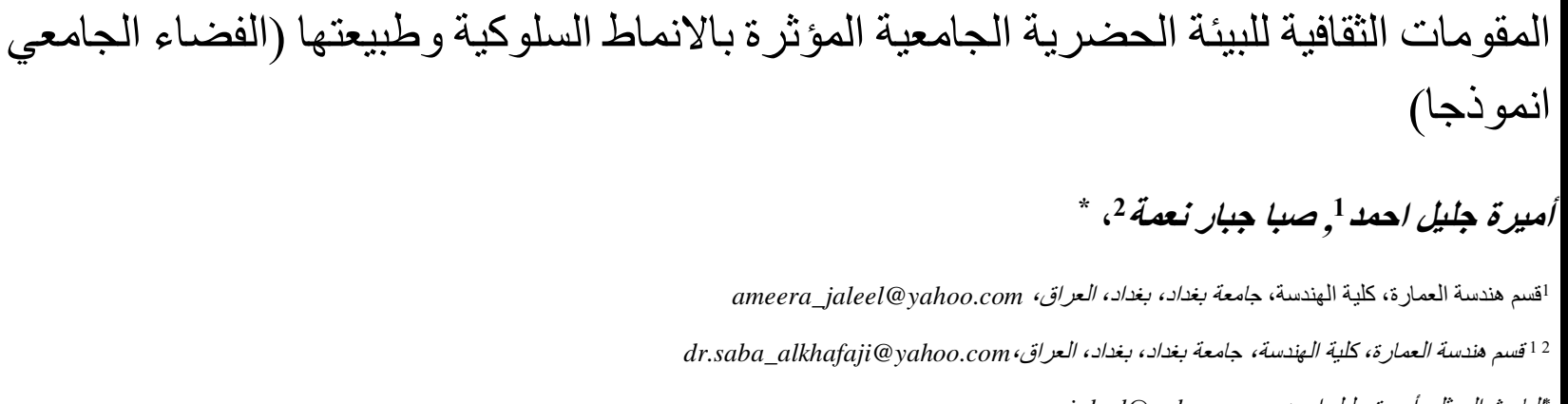
ameera_jaleel@yahoo.com الباحث المعثل: أمبرة جليل /حمد،

نشر في: 31 اذار 2021

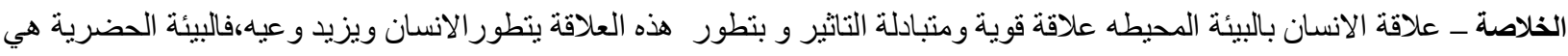

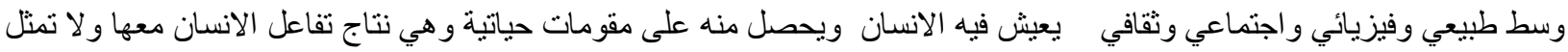

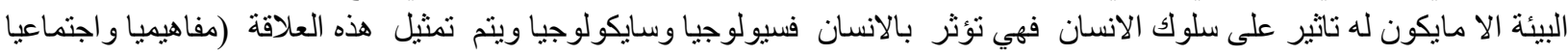

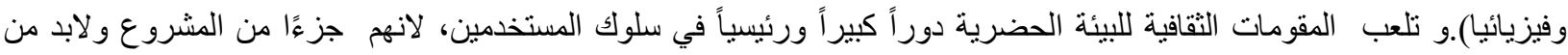

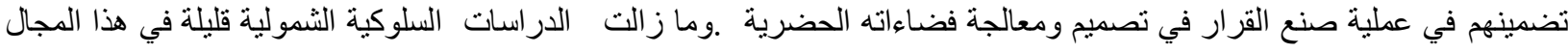

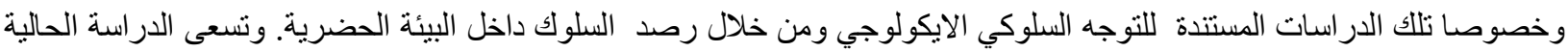

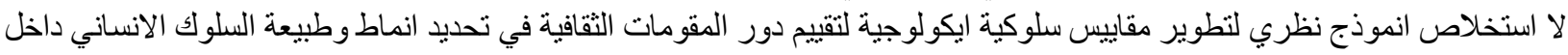

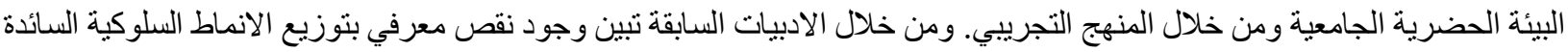

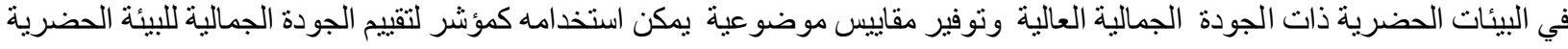

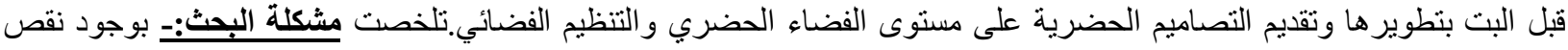

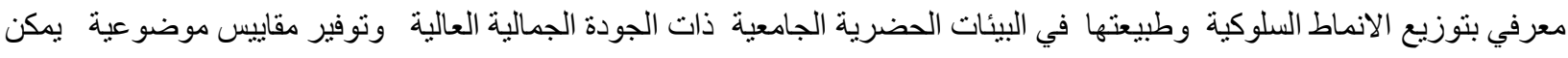

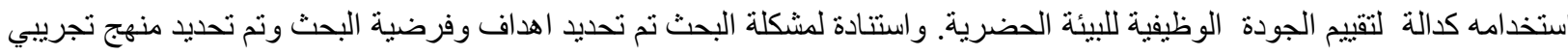

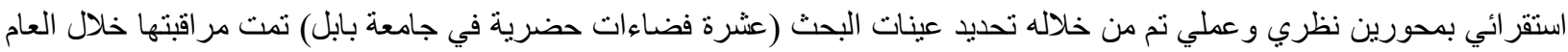

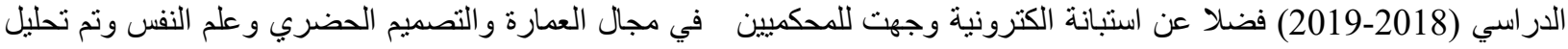

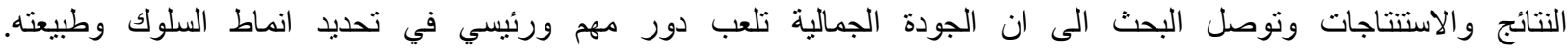

الكلمات الدفتاحية:- "الكقومات الثقافية" ،"الجودة الجمالية للبيئة الحضرية"، " الجودة الوظيفية للبيئة الحضرية"،"انماط السلوك"، طبيعة السلوك"

(والموروثات الحضارية)ووسائل التعليم الثقافي وهدفها تحقيق الجودة

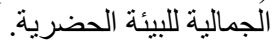

تكمن اهمية البحث في دراسة المقومات الثقافية للبيئة الحضرية كمنظومة الانهانة

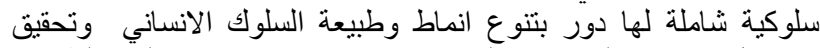

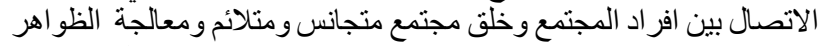

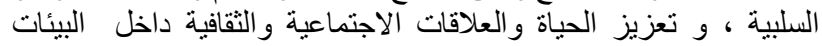

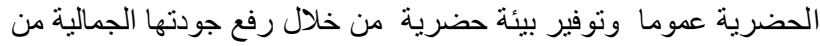

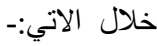

تحقيق انموذج نظري منطقي لتقييم البيئة الحضرية وظيفيا من خلال

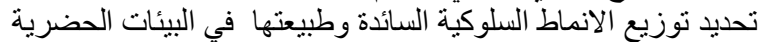

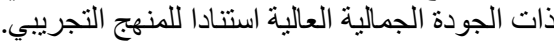

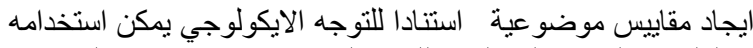

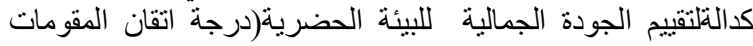
الثقافية في البيئة الحضرية) من خلال الجودة الوظيفية (طبية الئة وانماط اليفات

(السلوك)

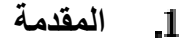

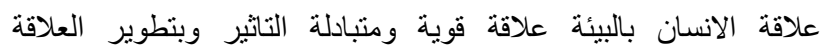

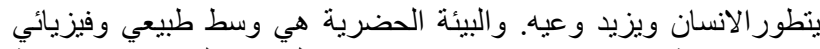

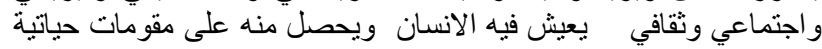

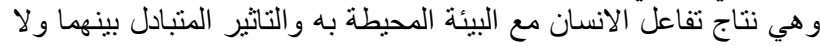

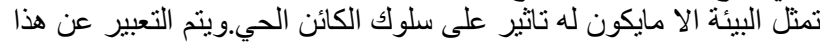

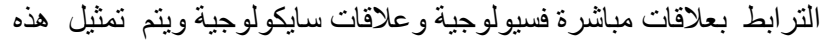

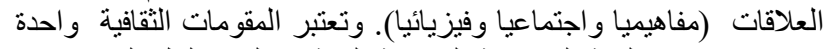

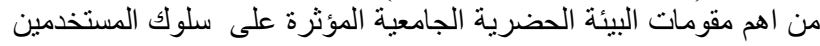

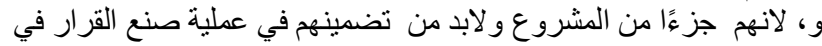

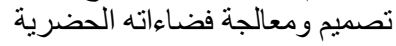

تطورت علاقة الانسان بمقومات البيئة المحيطة حسب تحقيقها

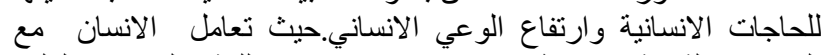

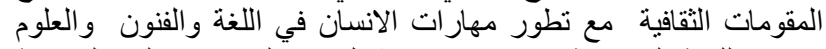

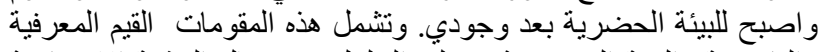

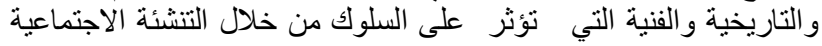




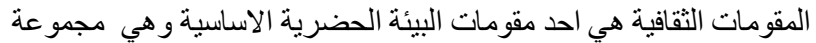

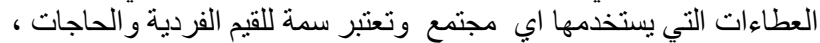

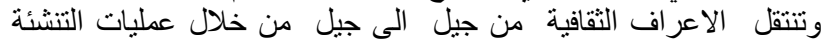

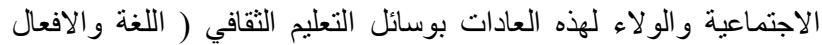

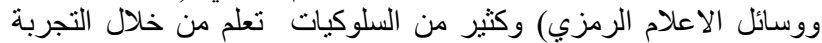

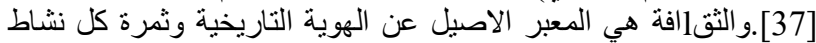

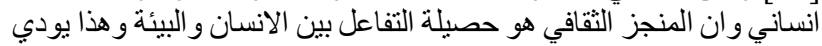

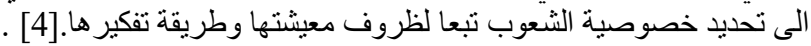

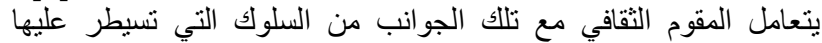

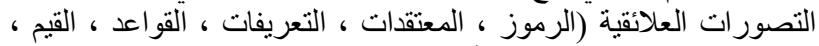

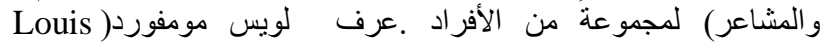
(Mumford

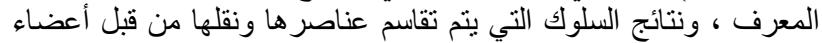

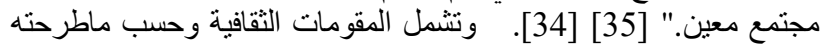

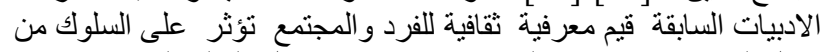

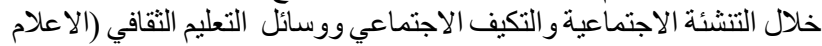

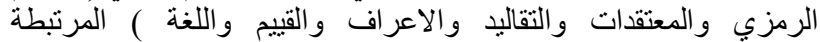
بالمجنمعات و الموروثات الحضارية.) [38] ، [42] [43] [27] [48].

\section{الجودة الجمالية والبصرية}

الجودة لها معاني مختلفة لأشخاص مختلفين وهي مفهوم متعدد الجوانب

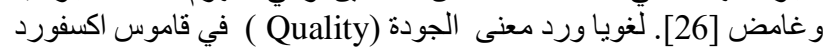

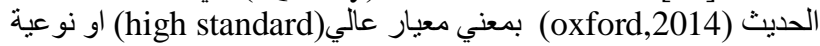

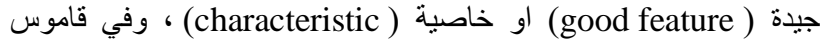

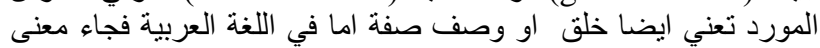

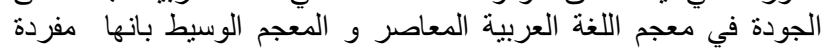

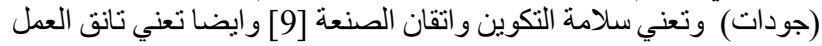

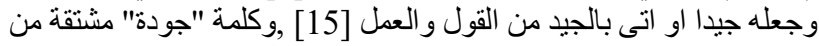

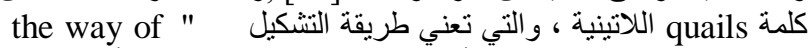

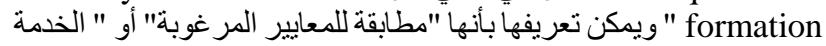

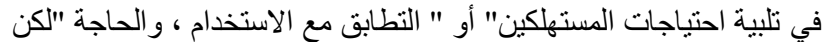
في الأدبيات تعني قابلية العيش ونو عية الحياة .

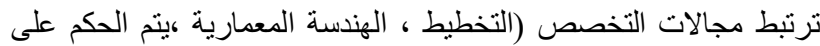

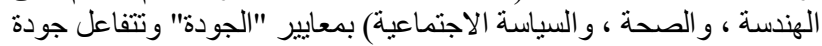

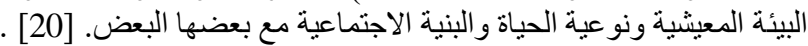

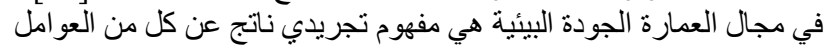

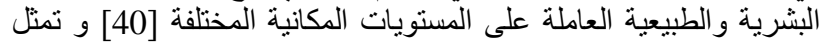

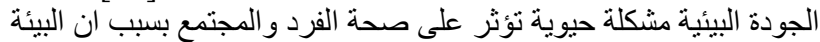

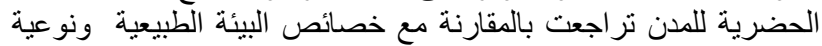

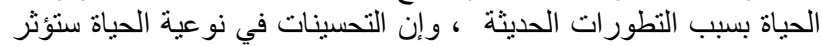

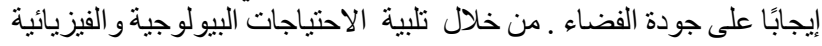

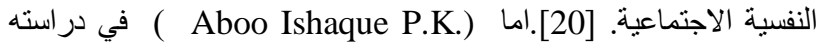

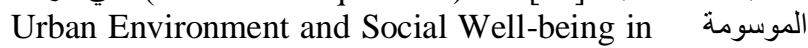
(Calicut City12012)

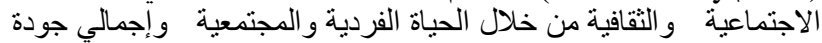

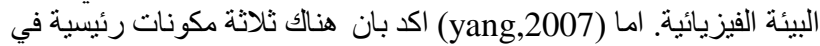

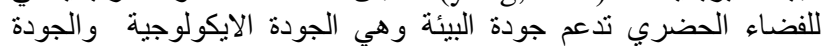

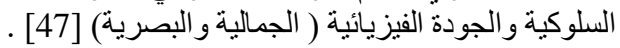

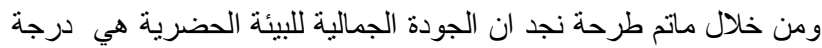

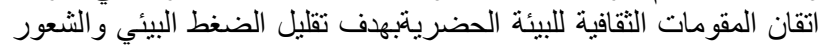

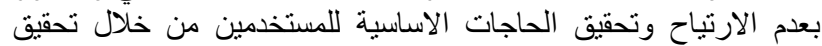
الحاجات الانسانية الاساسية . وتانثير اتها بانماط وطبية لإنة السلوك وتعتبر محد

\section{الحرم الجامعي Campus}

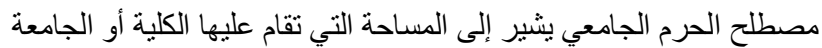
و المنشآت الأخرى المرتبطة بها (قاموس أكسفورد) ، اما كلمة (Compus)

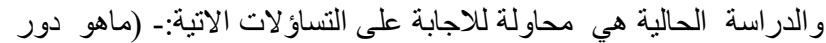

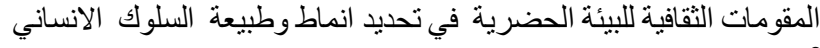

و هل هنالك علاقة تر ابطية بين الظاهرتين يمكن قياسها بو هل توجد امكانية

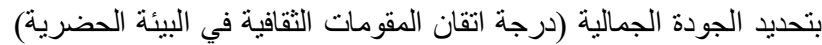
من خلال تحديد جودتها الوظيفية السلوكية (انماط وطبيعة السلوكية التول استتادا

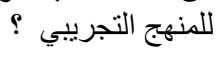

و هل تضمنت النظريات السلوكية تفسير شمولي لهذه العلاقة ؟

وماهي المقاييس الموضوعية التي طرحتها هذه النظريات لفحص العلاقة استنادأ للتوجه الايكولوجي ؟ ؟).

ومن خلال الاطلاع على الادبيات السابقة لوحظ شحة الدراسات الثمولية

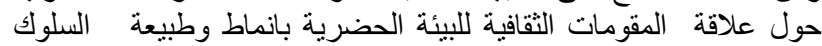

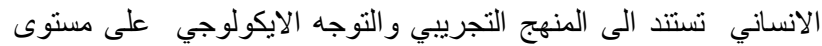

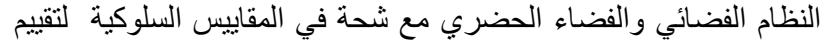

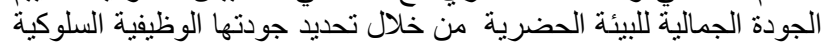

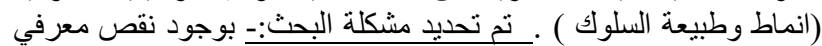

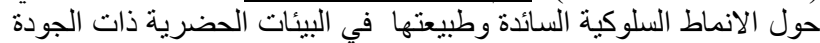

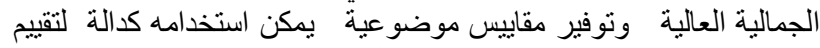

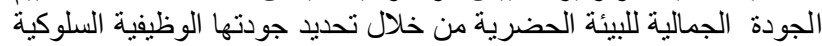

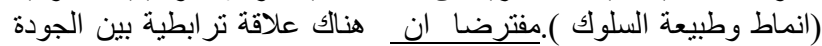

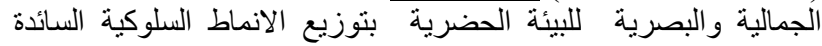

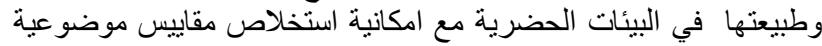

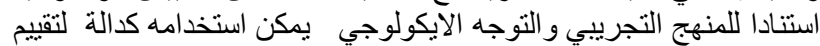

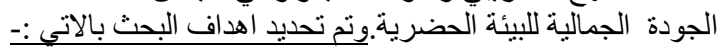

اظهار دور وتاثير المقومات الثقافية للبيئة الحضريةتبتزيع انماط وطبيعة السلوك في البيئة الحضرية.

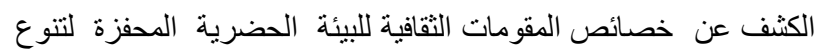

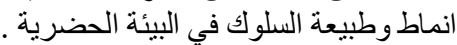

تحديد انماط السلوك السائد في البيئة الحضرية على مستوى الفضاء

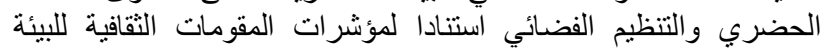

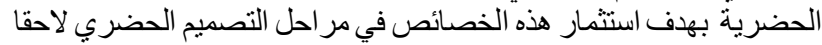

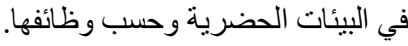

استخلاص وبناء مقاييس سلوكية موضو عية لتقييم الجودة الجمالية للبيئة

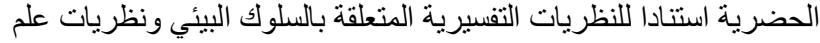
الاجتماع و العلوم الاساسية الرياضية الفئية.

\section{Specifying the Basic المصطلحات الأساسية للبحث Terms}

\section{cultural (المقومات الثقافية للبيئة الحضرية \\ (Constituents}

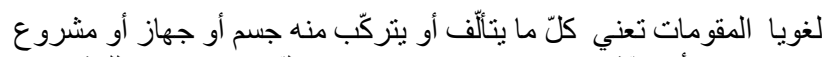

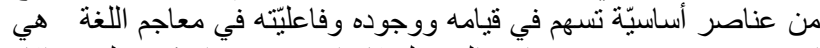

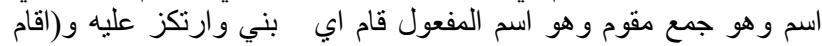

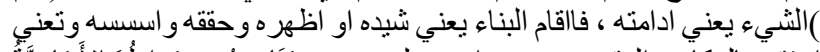

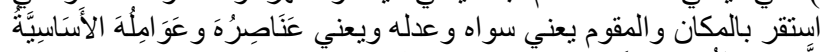

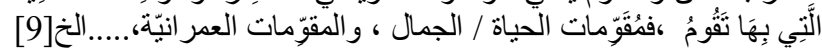

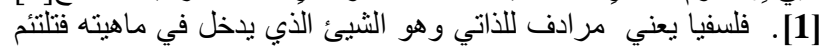

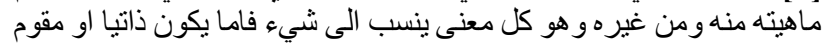

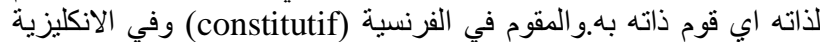

.[12] ، [8](constitutive) 
السلوك الانسانسي

السلوك هو مصطلح يشير الى اي فعل او ردة فعل تجاه شيء (object)

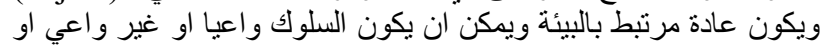

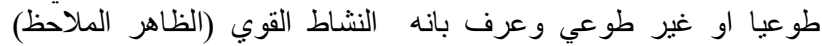

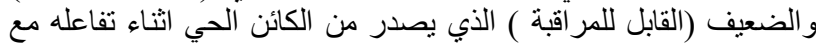

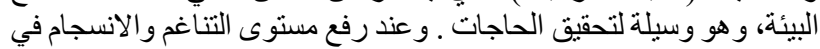

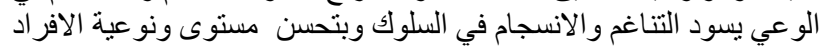

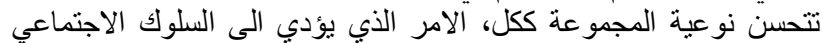

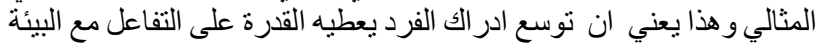

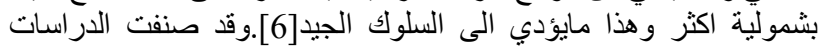

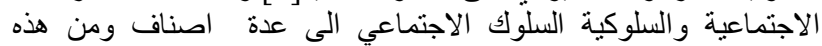

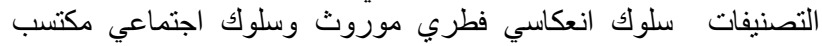

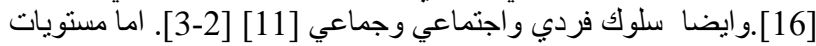

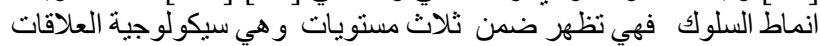

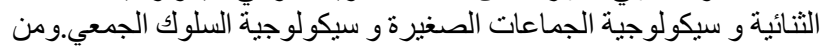

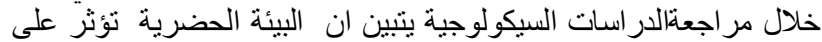

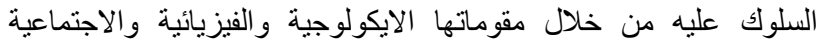

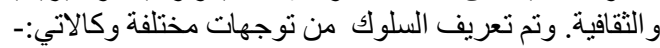

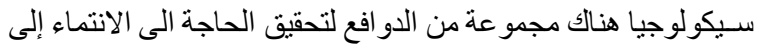

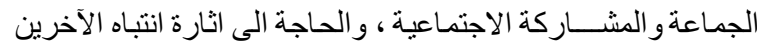

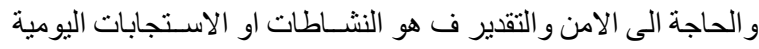

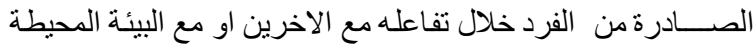

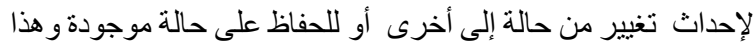
النشاط هو انعكاسًا لميول الفرد ولئ وطموحاته.

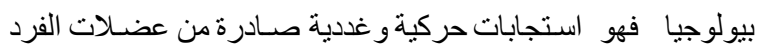

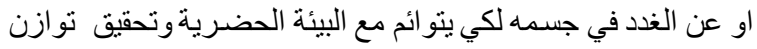

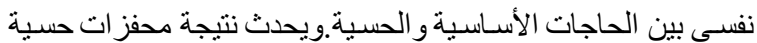

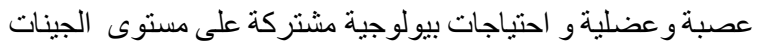

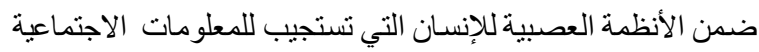

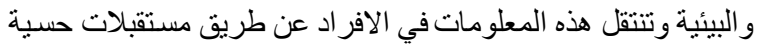

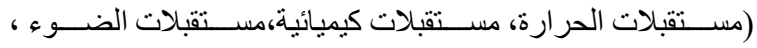

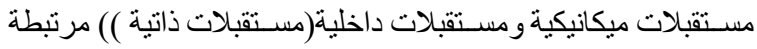

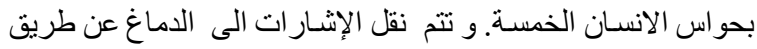

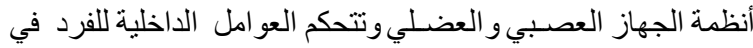
النشاط السلوكي النهائي. اجتماعيا" يعني " كل ما يصــدر عن الإنسـان من نشـاط ســو اء أكان

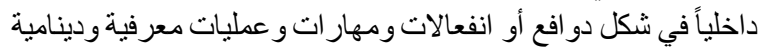

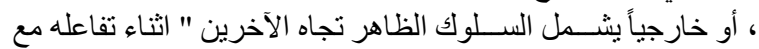

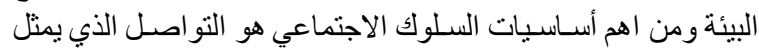

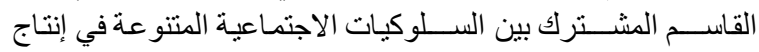

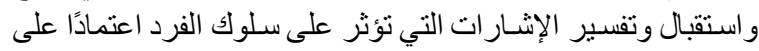

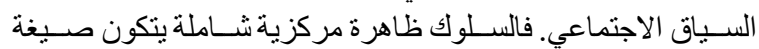

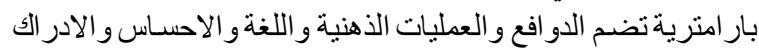

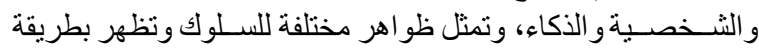

منطقية ومفاهيمية [35] [22] [50] [35).

\section{الدراسات العامة التي فسرت المقومات الاثثقافية للبيئة الحضرية كمؤثررئيسي في خصائص السلوك الانس النساني}

وهي مجموعة من الدراسات الانثربولوجية التي ناقشت علاقة المقومات

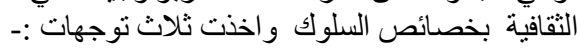

م التوجه الاول هو ارتباط السلوك بالنظم الاجتماعية

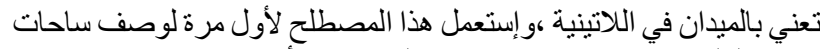

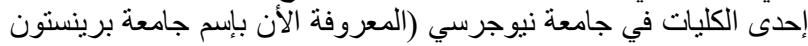
(Princeton university

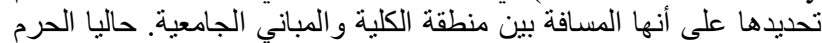

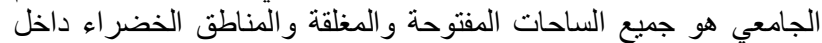

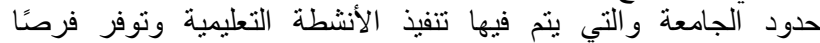

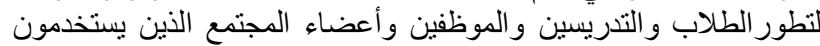

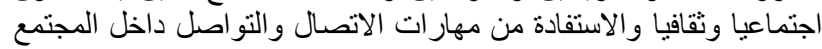

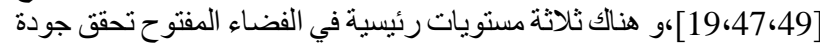
البيئة الجامعية مستويات وكالاتي :-

الجودة الايكولوجية وهذا يدعم خصائص البيئة الطبيعية من خلال

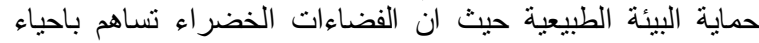

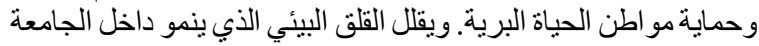
وفي المجتمعات المحيطة بها.

الجودة الوظيفية وهذا يدعم التفاعلات بين الســوك البشــري في البيئة

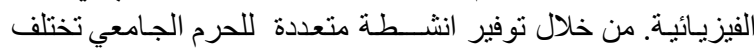

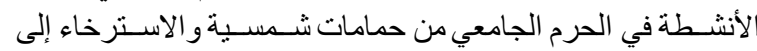

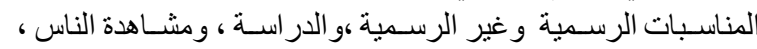

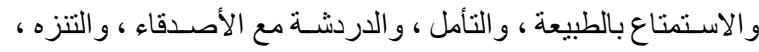

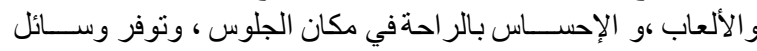

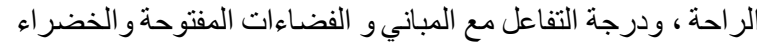

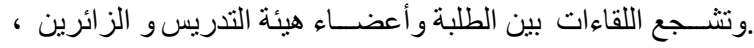

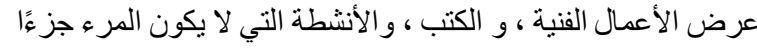

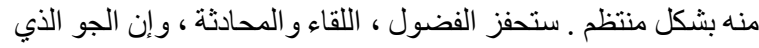

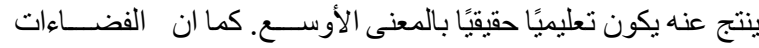

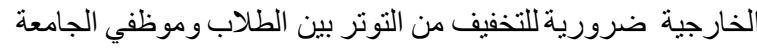

، مما يجعل التجانس بين الطبقات ، و العمل المكتبي أكثر احتمالا.

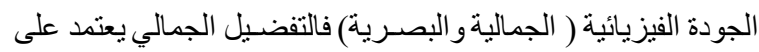

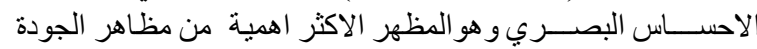

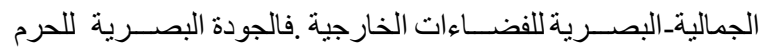

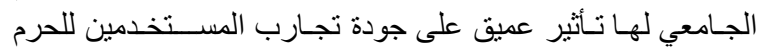

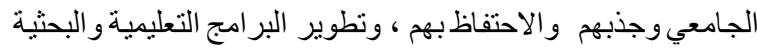

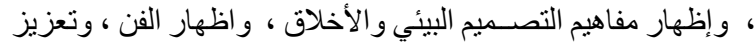

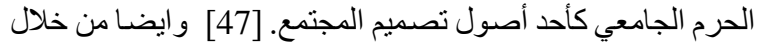

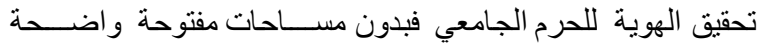

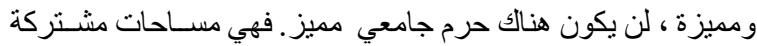

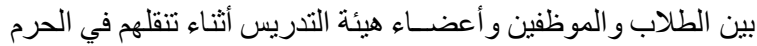

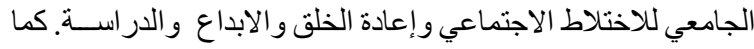

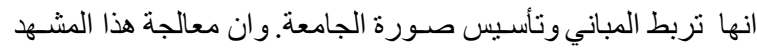

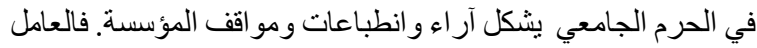

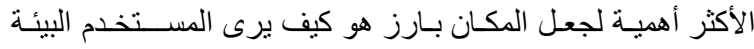

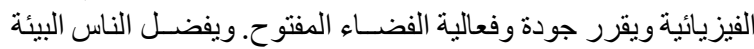

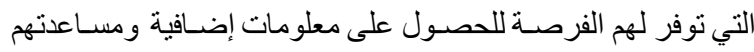

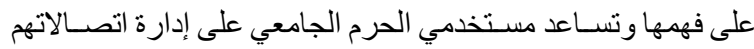

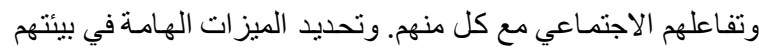

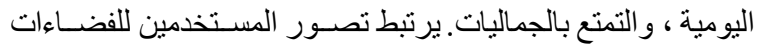

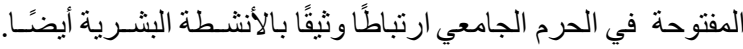

و استتادا للار اسات السابقة فقد مرت مقومات الثقافية للبية الجامعية بخمسة مراحل تطورية [4، [4،

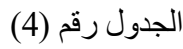


بنشاط مع البيئات الطبيعية و المعمارية و الاجتماعية و الثقافية التي نعيش فيها.

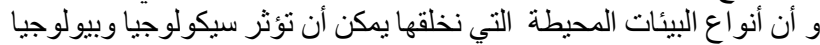

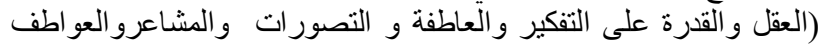

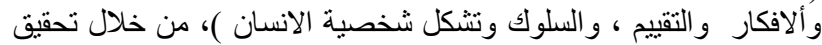

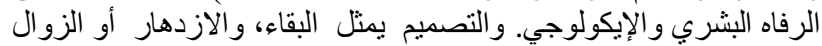

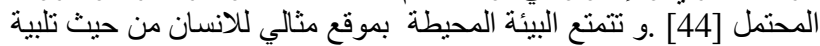

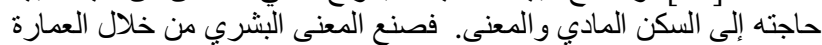

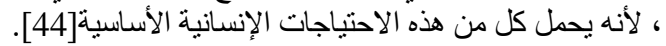

\subsection{4}

A Theory of ) اكد مقدمة كتابه Nikos Salingaros

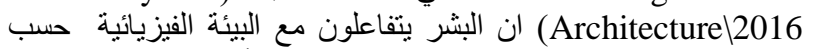

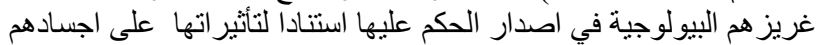

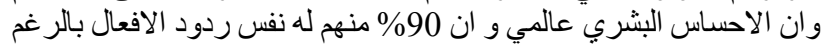

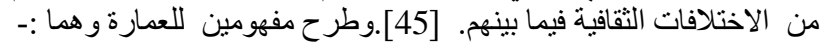

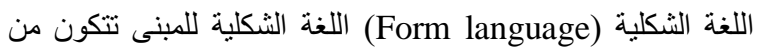

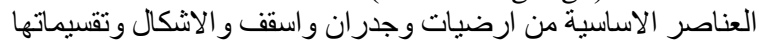
و النو افذ و المواد و الزخارف الزف وقيات واعد جميعها ضمن تكوين معماري وضمن سياق لغة شكلية محدد.

اللغة النمطية( Pattern language) تحددت بتكيف السلوك البشري

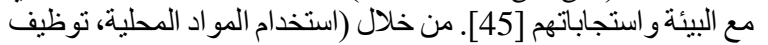

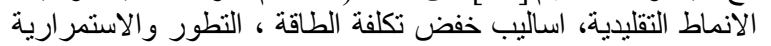

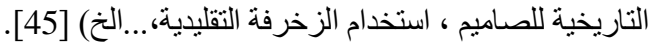

\section{(Kevin Lynch 1960) دراسة كيفن لينج}

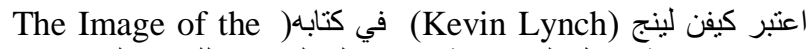

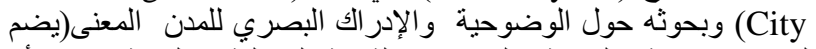

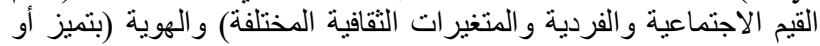
تفرد العنصر في المدينة) هي من المسنويات الاساسية للبيئة الحضرية [38]

$$
\text { دراسة (Shulz, 1971) }
$$

في كتابه (Existence Space and Architecture) يرى ان الفضاء هو

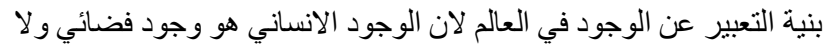

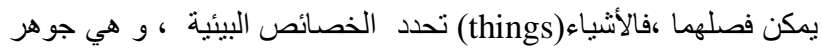

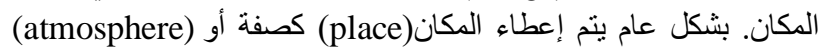

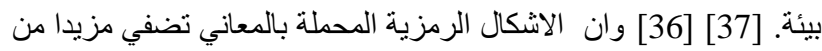

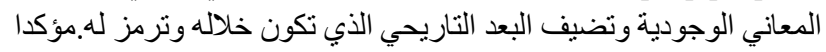

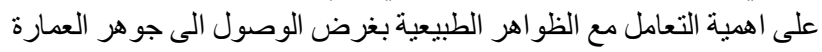

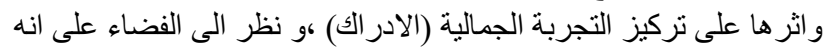

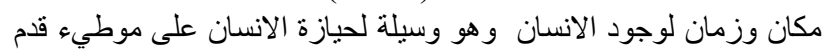

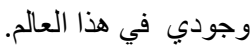

\section{دراسة (Gordon Cullen\1971)}

Townscape" ركز كولن على الصفات الجمالية، في كتابه مشهد المدينة

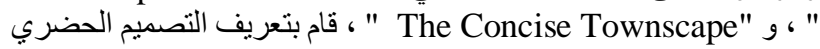

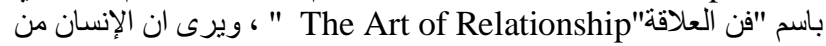

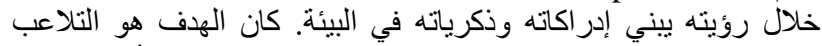

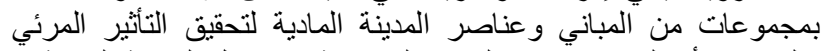

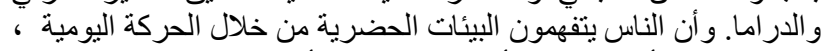

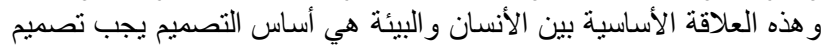
المدن من وجهة نظر الشخص المتحرك. حيث ركز غلئه الانوردن كولين وقبله كاميو

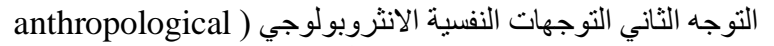

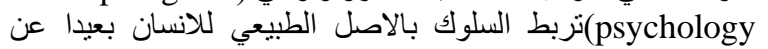

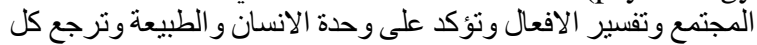

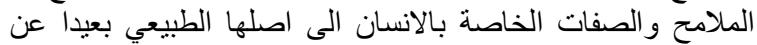

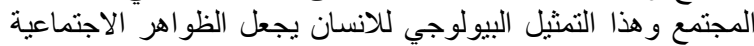

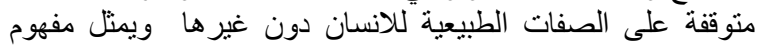

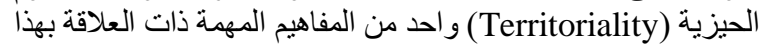

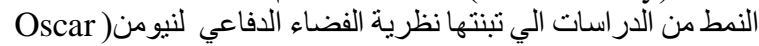
(Newman وونظرية الحيز الفضائي (Jane Jacobes)

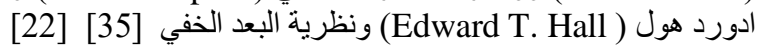

التوجه الثالث ربط السلوك الاجتماعي بالمقومات الثقافية للبيئة الحضرية التوحة

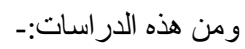

دراسة كاميلو سيتي (Camillo Sitte)

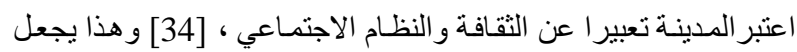

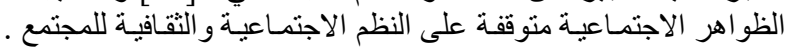

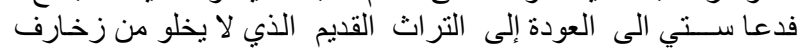

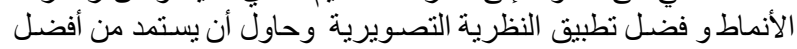

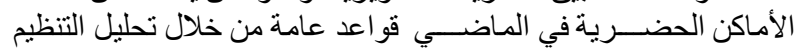

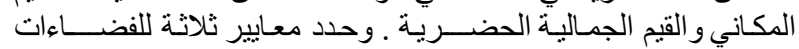

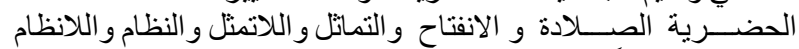

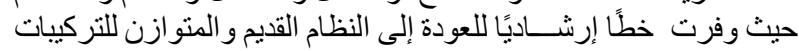

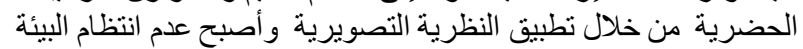

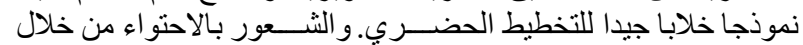

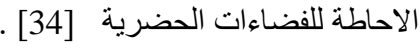

(Rapoport, 1977) دراسة)

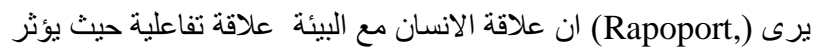

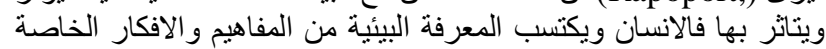

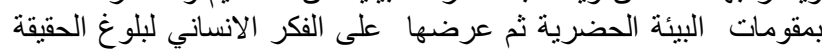

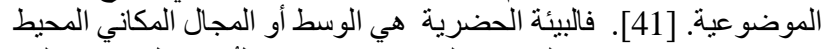

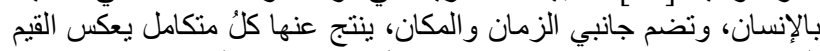

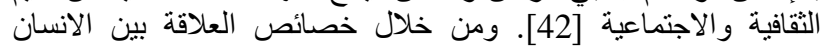

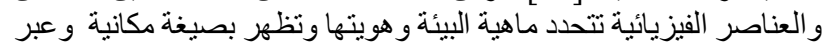
عنها بثلاث تتظيمات وكالاتي :- لتئي

م التنظيم المكاني المتمثل بعلاقات الفضاءات الحضرية والتنظيم الفضنئي.

تنظيم المعاني وياتي مع التنظيم الفضائي ويتمثل بمعاني الكتل ويعبر ونها بالاشار آت و الالّوان و المقياس وحددها من خلال و آلرموز البيئية و المنبهات الثقافية.

تنظيم الاتصال ويتمثل بالعلاقات بين الافراد في البيئة الحضرية

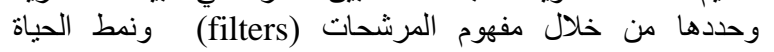
.[4] [41] (lifestyle)

Sarah Rabinson and Juhani ) دراسة 3.3 (Pllasmaa 2015

وهي دراسة نفسية انثروبولوجي ناقثت علاقة العمارة بعلم الأعصاب

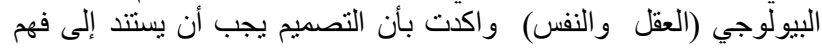

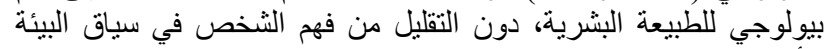

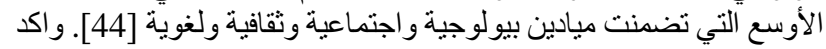

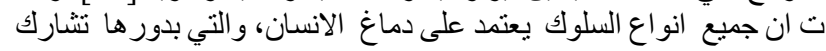


العالي يعتمد غالبًا على تصور هم للحرم الجامعي فهو يخلق الذكريات ويبني

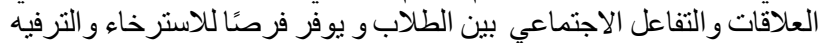

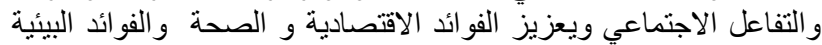

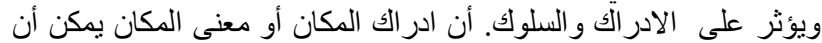

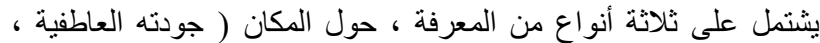

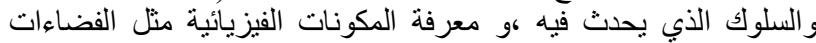

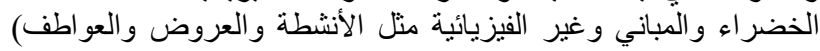

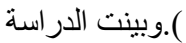

تؤثر الصفات الجمالية للحرم الجامعي وتصميمه و أسلوب إدارته على ادر الك

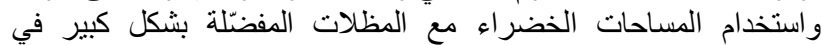

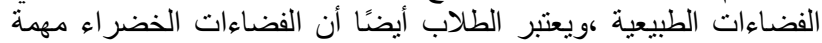

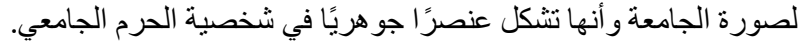

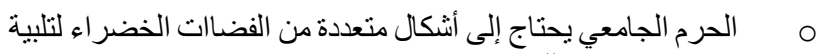

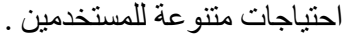

دور الوعي البيئي باهمية الفضاءات الخضراء كمؤثر بتفضيل جماليات الفضاءات المفتوحة واستخدامها.

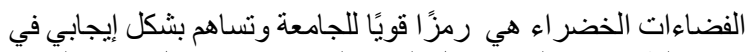

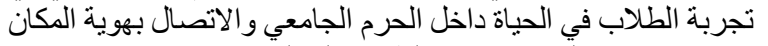
، و نوفر فرص لتحسين وعي الطلاب البيولوجي.

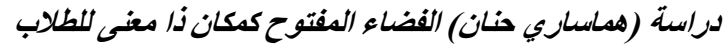 \\ في الحرم الجامعي (جامعة ITB في (ندنوسيا)/2013
}

Open Space as Meaningful (Himasari Hanan, Place for Students in ITB Campus)

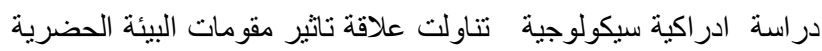

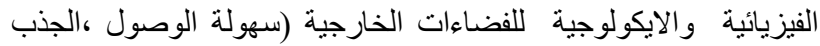

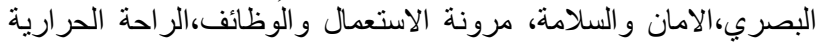

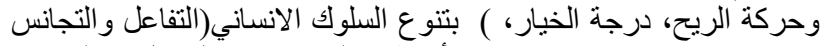

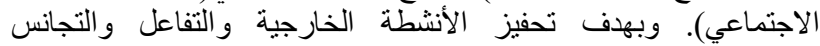

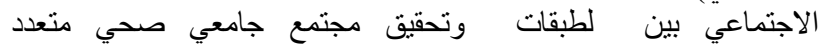

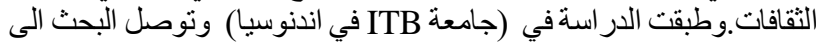

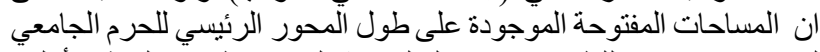

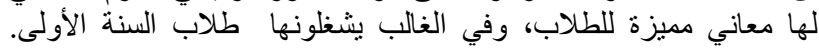

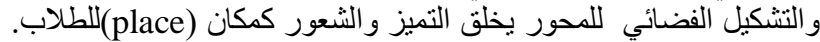

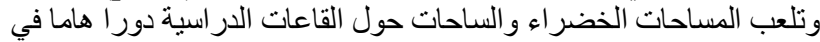

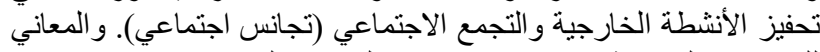

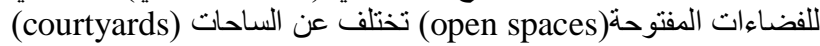

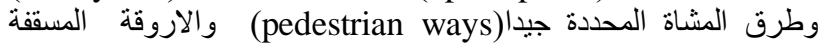
(corridor)

ركزت هذه الدراسات على دراسة علاقة دوروتاثير المقومات الثقافية

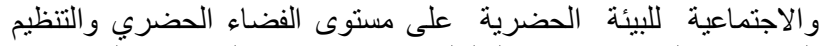

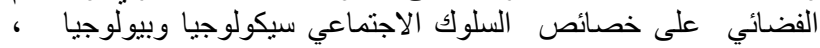

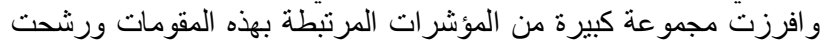

مجموعة من المؤشرات للاطار النظري والثرات المبينة في الجدول رقهم (3).

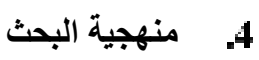

تم تبني_ منهجية استقر ائية تجريبية ضمن محورين:-

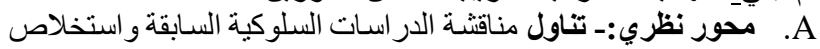

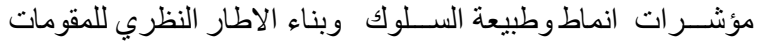

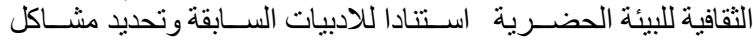
البحث وفرضياته و المنهجية.

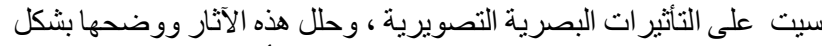

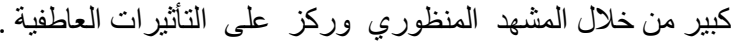

اذتم كولن بإلاحساس بالمكان ، الذي وضعه نظريًا من خلال مفهوم هذا

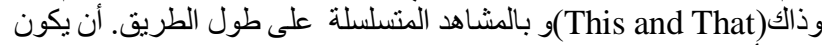

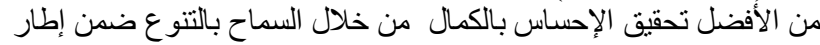

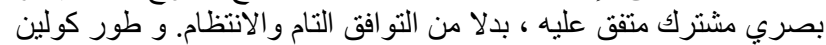

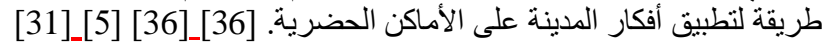

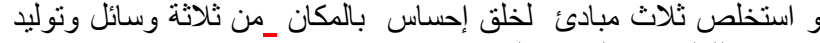

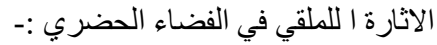

البصريات (Optics):- تشمل المشهد المتسلسل المتحقق من خلال التجاور والتناقض مابين المتجاور ات. طور مفهوم الرؤية المنسلسلة .

المكان (Place):- ويشمل وجود المقياس والاحتو اء ومفهوم التطويق

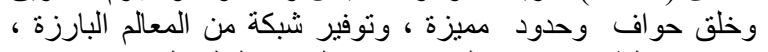

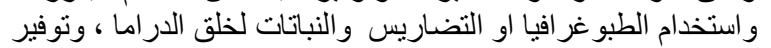

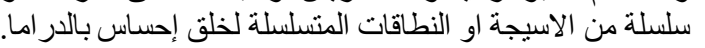

المحتوى (Content):- تشمل خصائص (اللون ، المقياس، الطراز، الطابع ، الخصوصية ( التصرد): التفرد).

Dicle Aydin and دراسة لبكلا /بين و /بيسي كالسون تيل Ummugulsum Ter الجامعي كحالة دراسبة)/2008

\section{OUTDOOR SPACE QUALITY: CASE STUDY OF A UNIVERSITY CAMPUS PLAZA}

دراسة سيكولوجية لحرم جامعة (Selcuk University/Turkey)

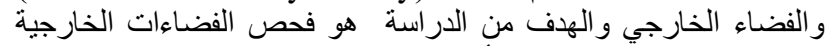

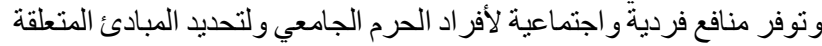

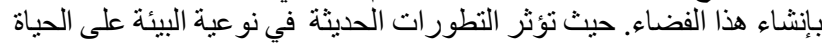

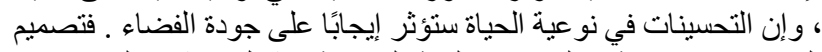

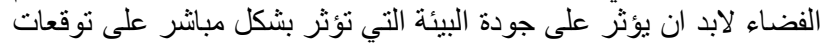

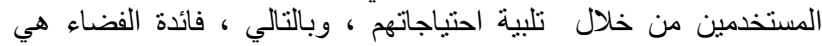

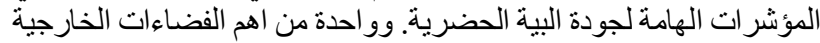

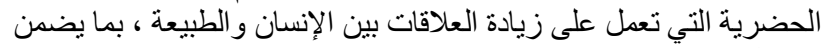

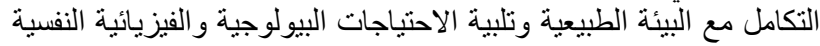

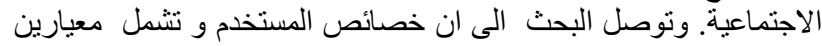

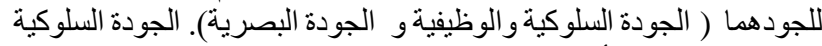

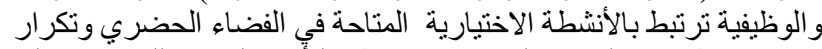

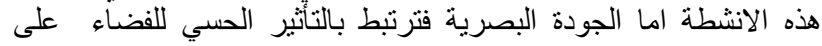

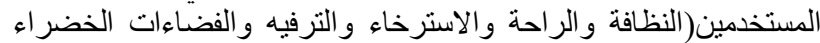
و الأمن) و هو يحد د جودة الحرم الجنامعي والانترخياء

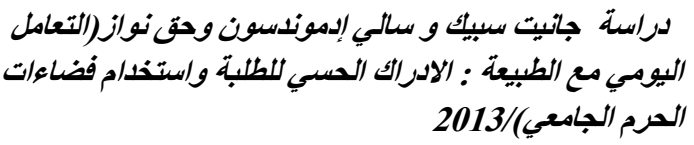

Janet Speake, Sally Edmondson, and Haq Nawaz,

(Everyday encounters with nature: students, of university campus green perceptions and use spaces $/ 2013$

Liverpool Hope ( دراسة سيكولوجية اجريت في جامعة ليفربول هوباء

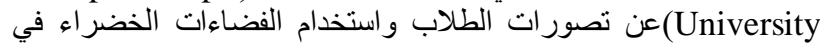

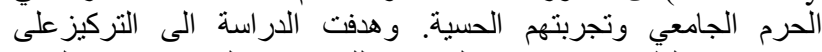

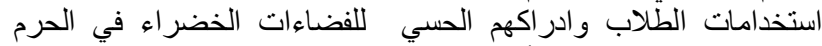
الجامعي لانها جزء لا يتجز أ من البيئة .و وان اختيار الطلاب لمؤسسات التعليم 


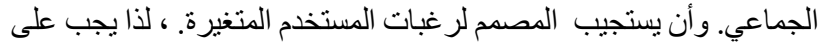

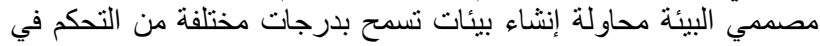

الاتصال مع الآخرين. [39].

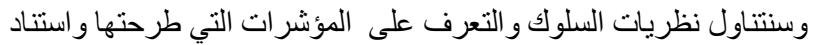

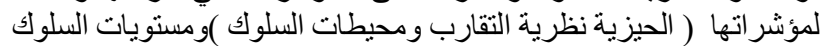

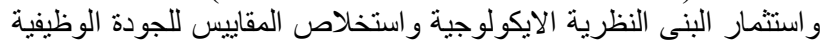

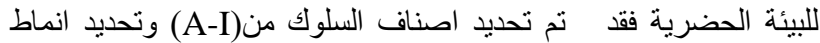

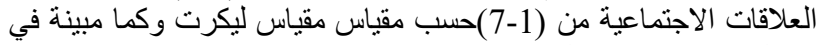

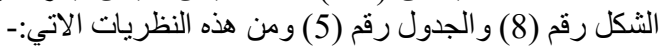

\section{(النظريات العيزية (territoriality theory)}

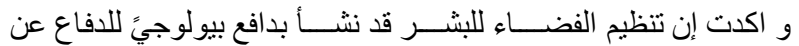

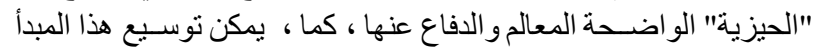

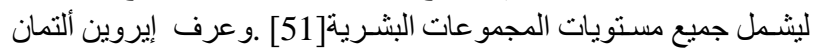
( Irwin Altman1975)

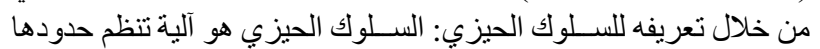

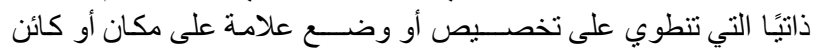

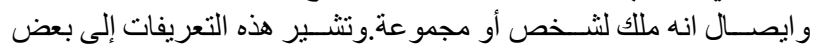

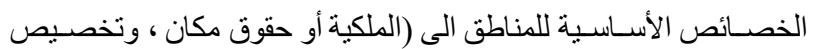

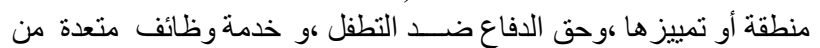

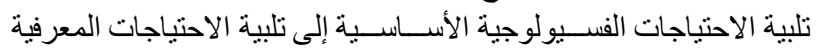

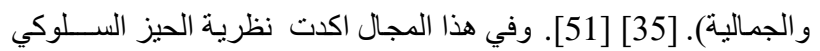
لجين جاكوبس(Jane Jacobs, Behavioral Territory,1961) التي وفي التئي درست (Jane Jacobs) الحيز السلوكي (Behavioral Territory) في (لفي

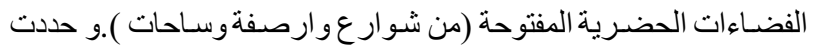

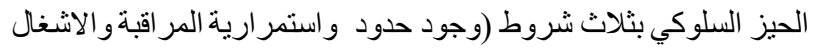

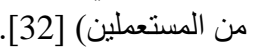

\subsection{1}

و هي مجموعة من النظريات و الدراسات ضمن علم النفس الايكولوجي كماتي

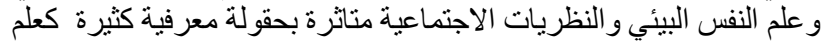
الايثولوجيا (Ethology) و العلوم السلوكية (Behavioral Sciences)

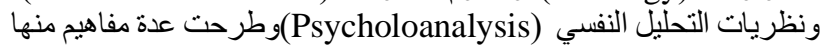

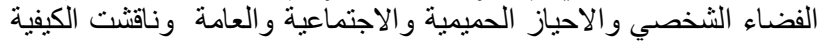
التي يرتبط بها البشر مع بعضهم البعض في البيئة الحضرية ولية وكيفية سيطرتهم

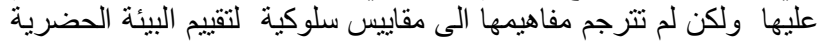
ومن هذه الدر اسات و النظريات نظرية ) Edward T. Hall: Proxemic Robert Sommer, Personal Space)g (Theory, 1966 (Kurt Lewin: Field Theory )و (theory1969

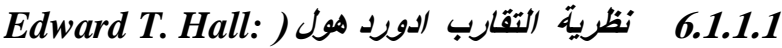 (Proxemic Theory, 1966}

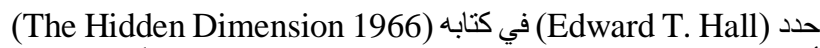

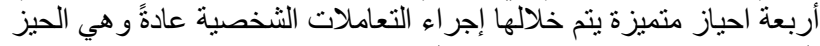

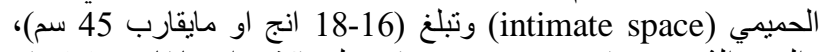

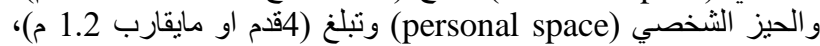

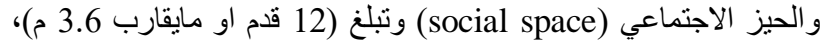

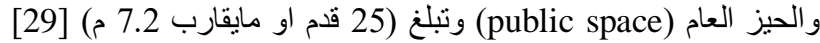

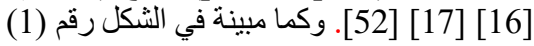

Robert ( 6.1.1.2 (Sommer,Personal Space theory1969

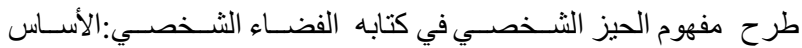

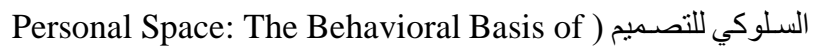

B

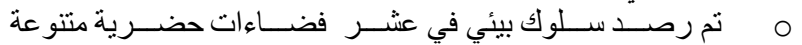

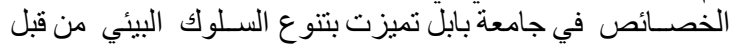

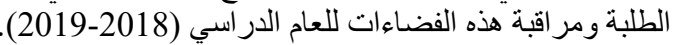

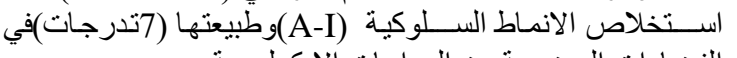

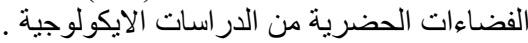

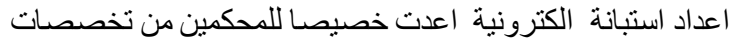

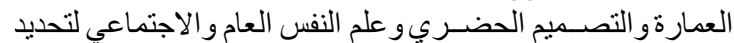

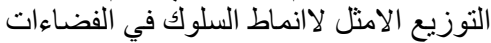

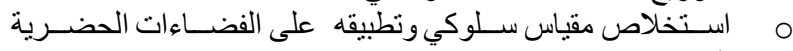

م تحليل النتائج من خلال البرامج الاحصــائية (Excel)ور(SPSS) و استخلاص الاستنتاجات و التوصيات.

بناء مؤشرات الاطار النظري للجودة الجمالية

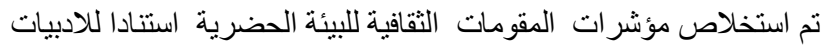

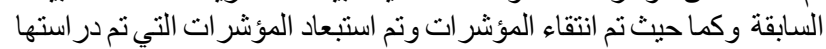

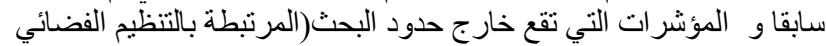

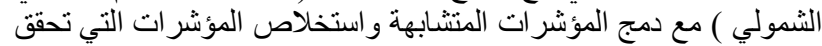

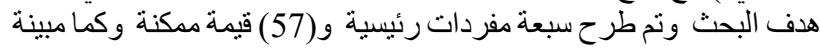

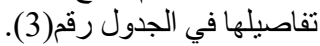

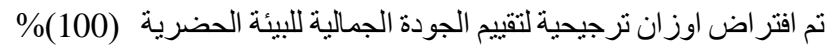

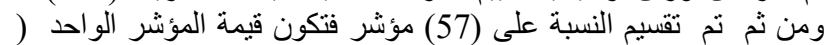

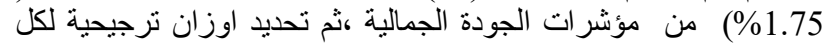

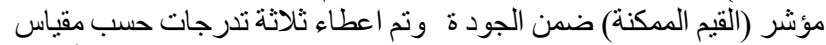

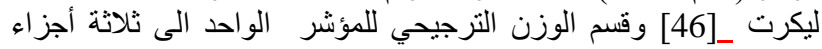

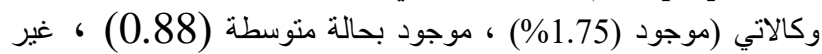

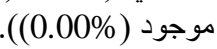

انماط السلوك

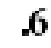

ترتبط مفاهيم الخصوصية و السلوك الحيزي و الفضاء الثخصي ارتباطًا

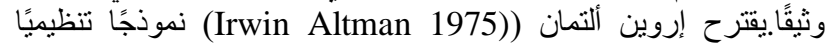

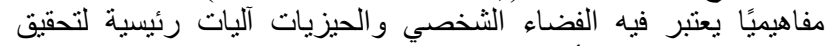

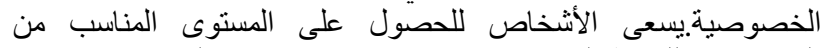

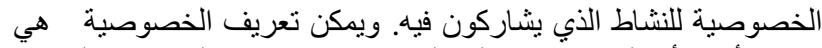

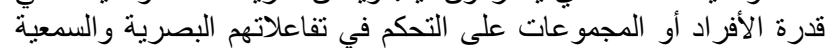

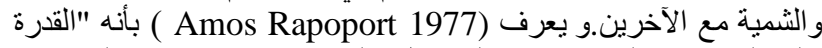

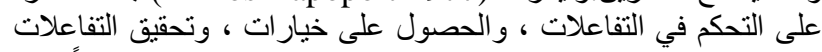

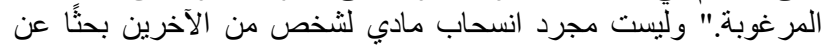

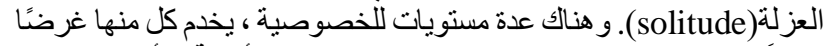

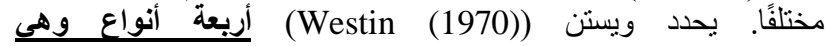

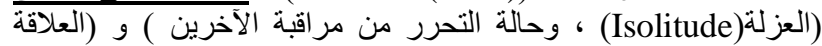

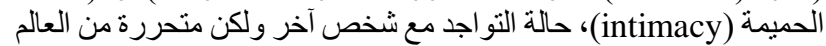

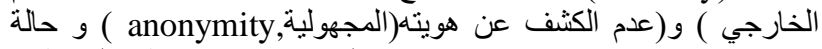

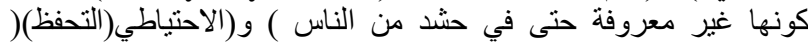

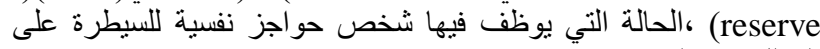

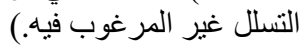

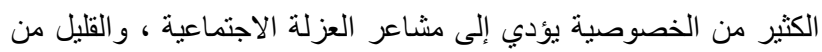

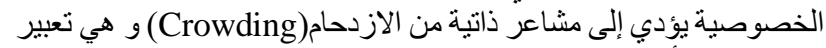

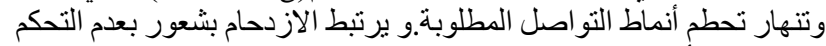

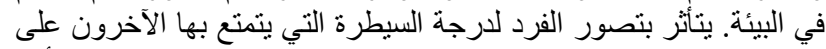

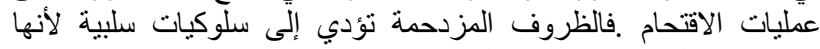

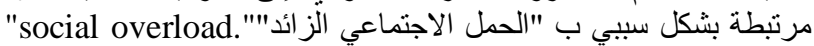

ويرى (PhD Ali Namazian,2013) ) انه لابد من ان نصمم بيئات متجاوبة ، والتي تسمح بالتناوب بين حالة الانفصال وحالة من العمل نص الن 
(Robert Bechtel (1977))

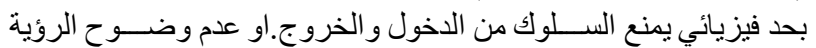

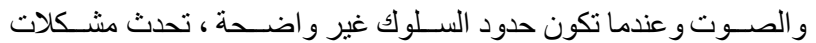

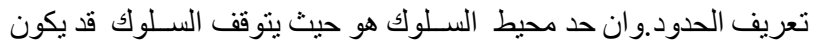

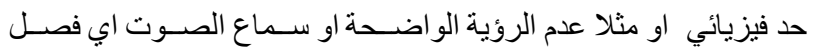

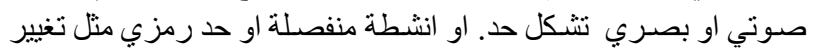

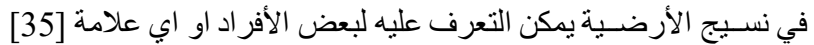
.[21] [30] [16]

\section{النظريات الاجتماعية}

هناك مجموعة من النظريات الاجتماعية التي شخصت طبيعة السلوك

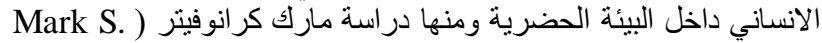

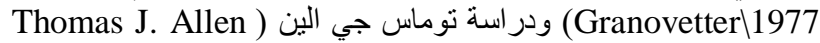

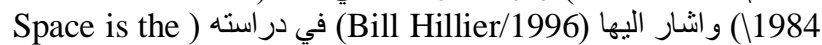

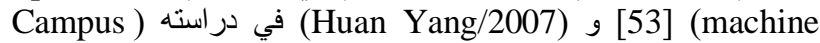
(47) (landscape space planning and design using QFD

مبينة في الثكل رقم (2)

\section{دراست(Thomas J. Allen \1984)}

6.4.1

تناول (Mllen) في در اسه (Managing the Flow of Technology) حول التو اصل و الآتكارفي منظمات العلوم و الهندسة ، مبينًا كيف يمكن إعادة الفئ

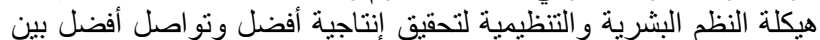
الأشخاص.طر ح (Allen) مفردة (chance meetings) اللقاءات العشو الئية او التصادفية في انتاج المعرفة الجديدة [13 [18 [18].

لدراسة (1977 Mark S. Granovetter)

6.4 .2

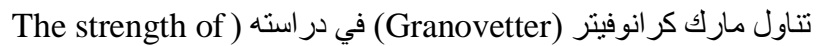
(weak ties

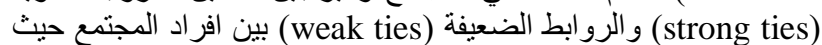

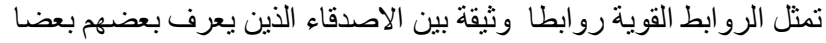

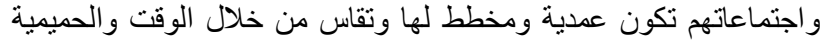

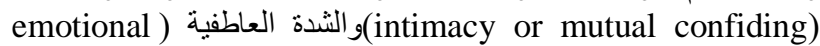
و و الخدمات المتبادلة (intensity

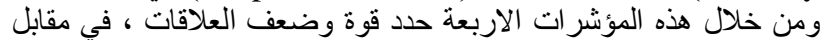

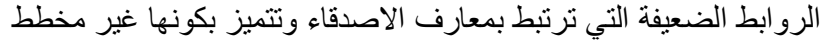

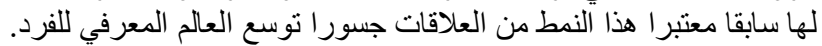

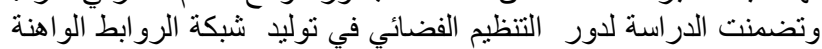

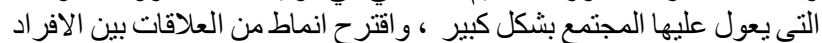

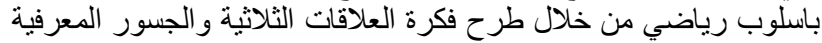

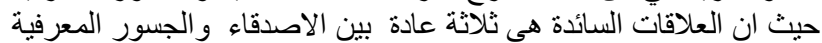

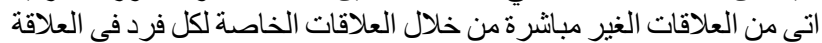

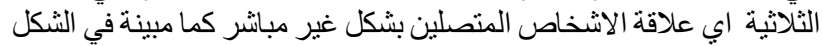

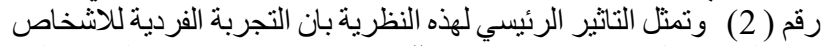

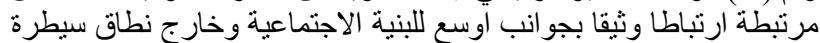

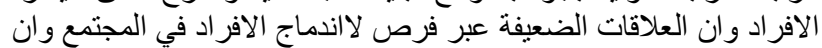

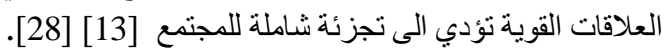

\section{العينات البحثية}

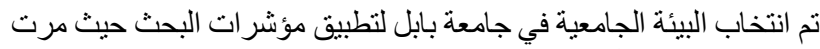

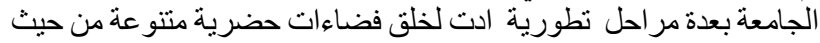

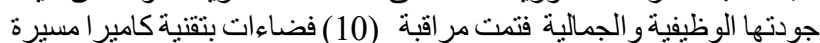

(1969) (Design ). تشبر المساحة الثخصية إلى منطقة ذات حدود غير

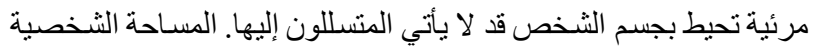
ليست بالضرورة كروية الشكل ، و لا تمتد بشكل متساوٍ في جميع الاتجاهات

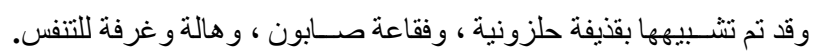

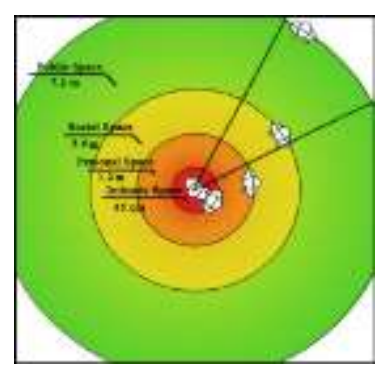

شكل رقم (1) :- يوضح انواع الحيزيات التي ينم فيها التعاملات الفردية وحسب تصنيف (Hall)
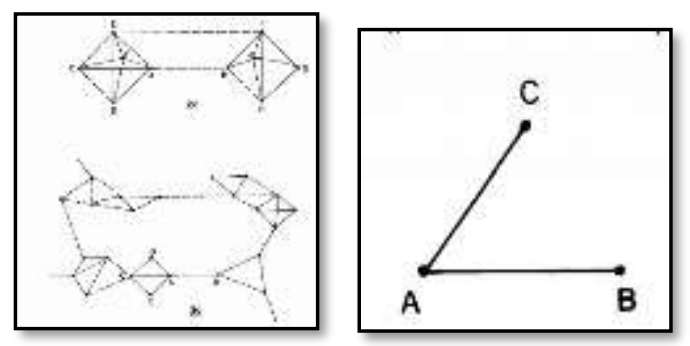

شكل رقم (2 ): انماط العلاقات التي اقترحها Granovetter في نظريته الاجتماعية

النظريات الادراكية

تتمثل بنظرية المجال(Field Theory) لكيرت ليوين (Kurt Lewin)

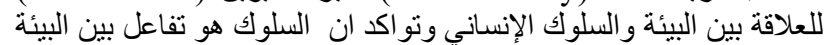

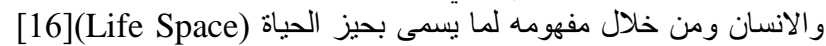

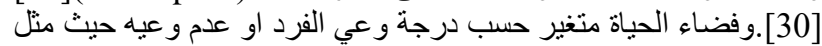

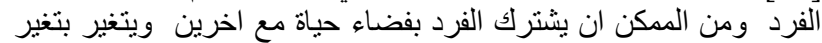

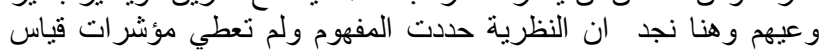

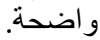

6.3

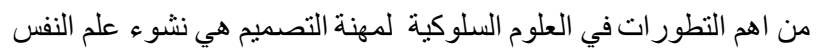

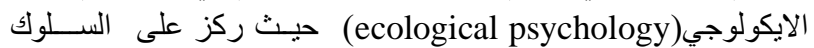

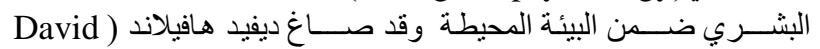

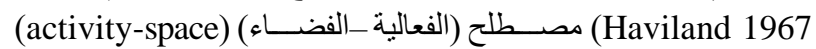

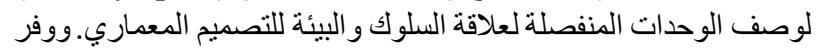

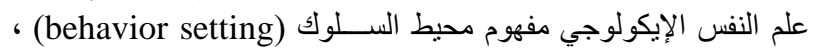

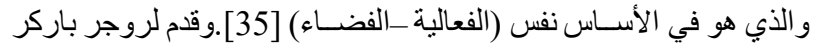
(Roger Barker1968)

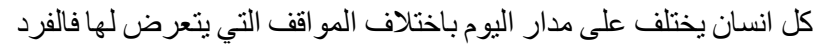

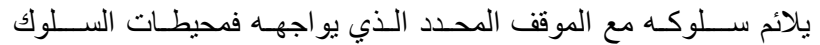

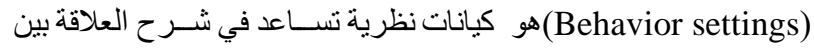

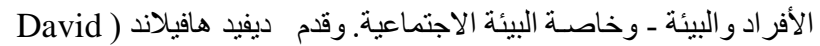

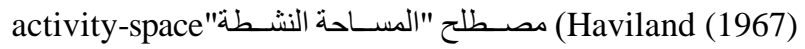

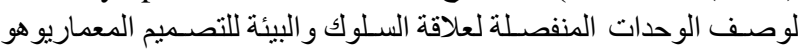

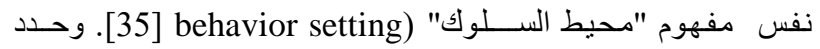




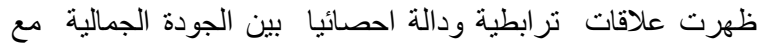

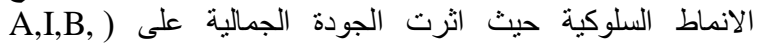

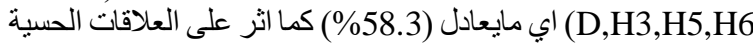

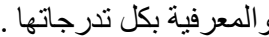

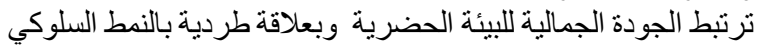

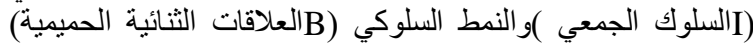

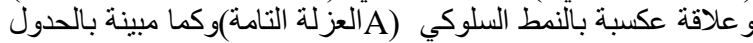

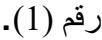

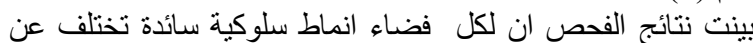

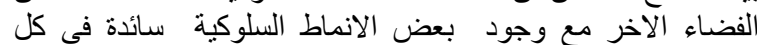

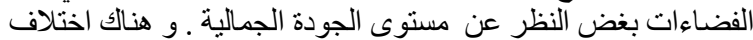

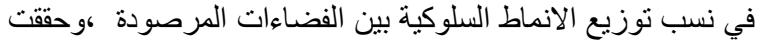

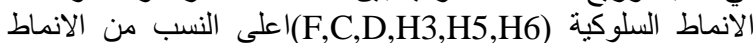

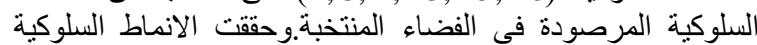

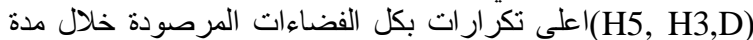

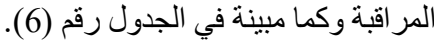

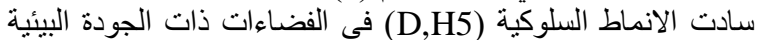

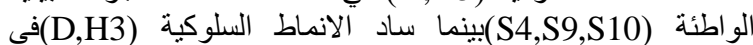

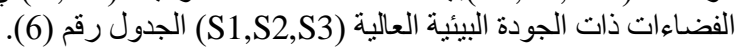
سادت العلاقات الحسية والمعرفية الضعيفة (T5,T6,T7) في مقابل فيل فئل انخفاض العلاقات الحسية والمعرفية القوية (T1,T2) في كل

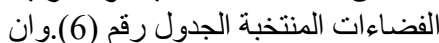
هناك تدرج وتو افق وتنوع وتناغم بتوزيع العلاقات الحسية والمعرفية الهية في الفي الفضاءات العالية)(S1,S2,S3,S5) الجدول رقم (7).

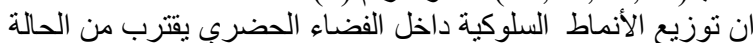

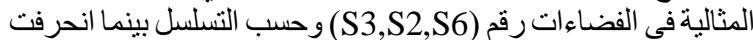
بشكل كبير في الفضاءات رقم)(S4,S7,S8,S9, في حين سجلت باقي

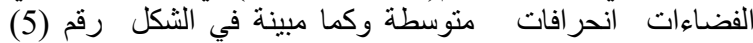

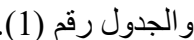

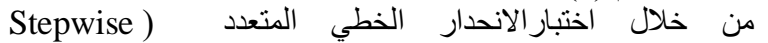
(Regreesion (A,D,H3,H5,I)

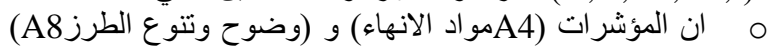

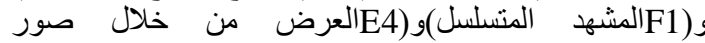
فوتغر افية)و(E3 العرض من خلاتل حركة السيارات) و

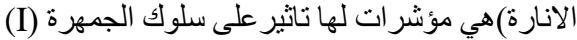

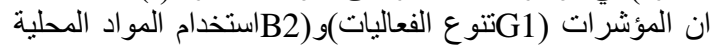

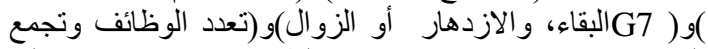

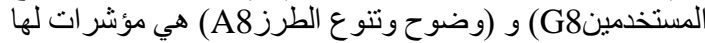

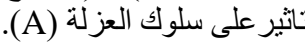

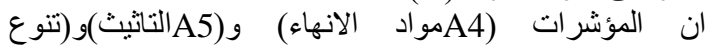

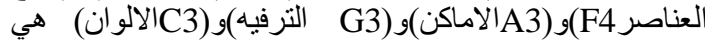

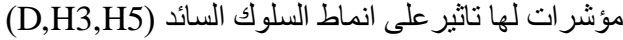
المفردات الرئيسية المؤثرة على انئل اغلب الانماط السلوكية (A,D,H3,H5,I)

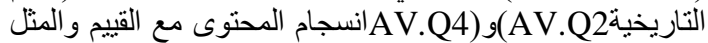

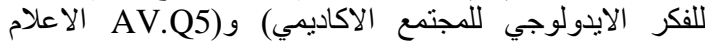

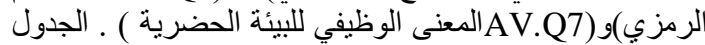

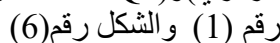
المفردات الرئيسية المؤثرة على سلى سلوك الجمهرة (I) الوكي

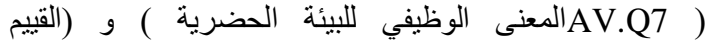

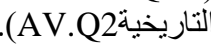

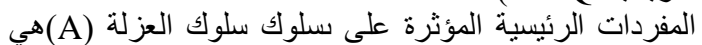

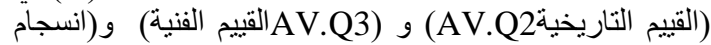
(AV.Q4 المحتوى مع القييم والمثل التعليمية (AV)

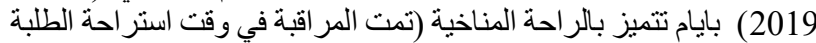

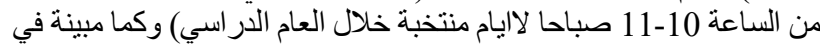

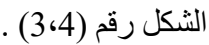
(c (d (e (f
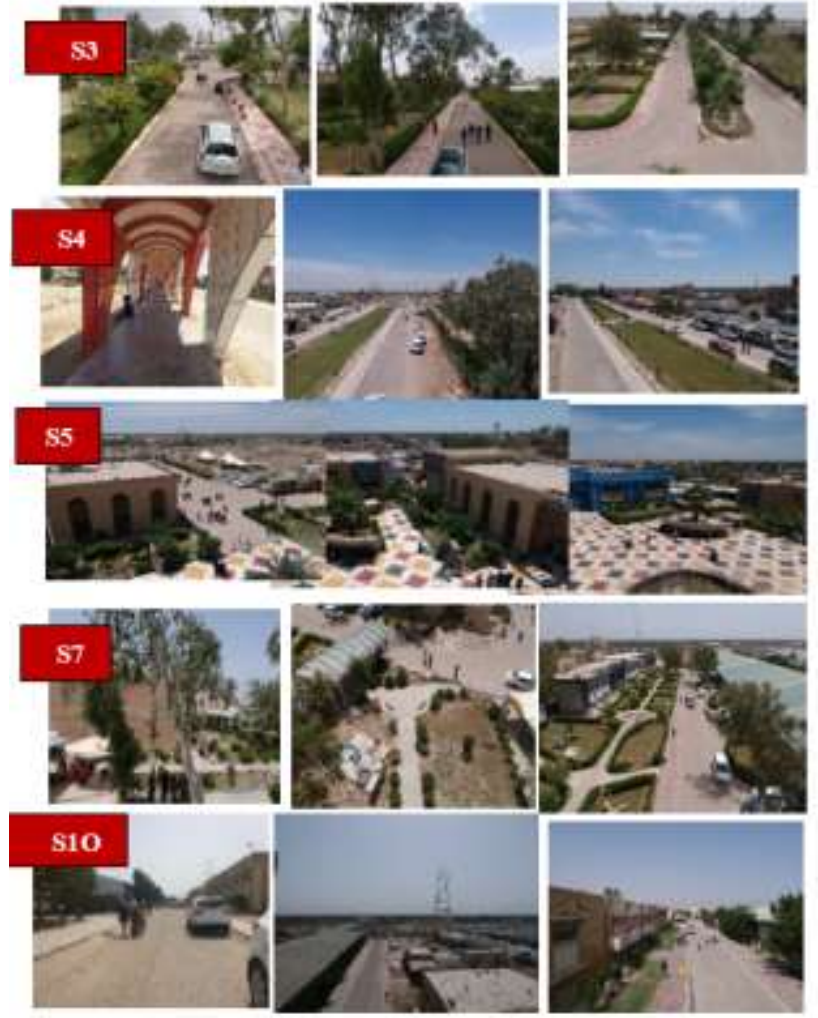

شكل رقم ( 4 ):- رصد انماط السلوك في العينات المنتخبة

النتائج

\section{8}

a

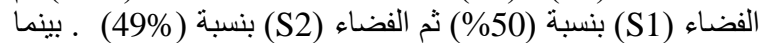

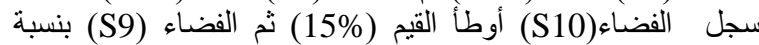
(16\%) ثم الفضاء (S4) بنسبة (19\%) (19\%) من منطلبات الجودة الجمالية

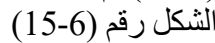




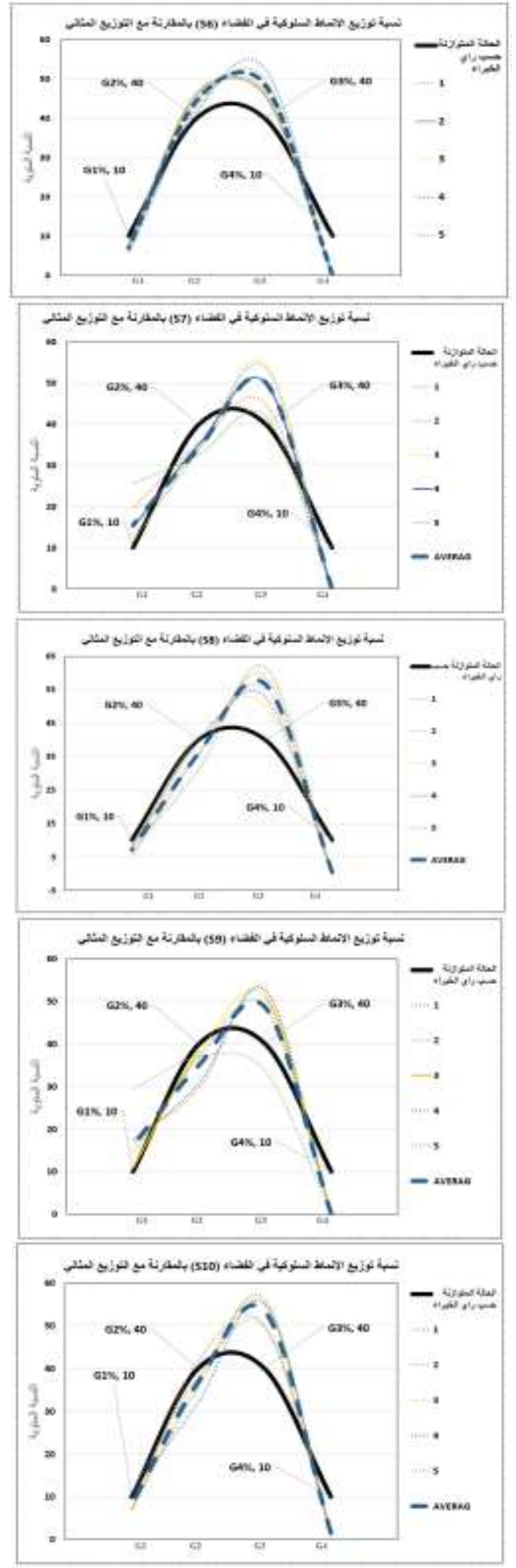

شكل رقم ("5):- نسب توزيع الانماط السلوكية في الفضاء المنتخبة

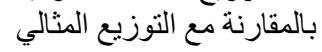
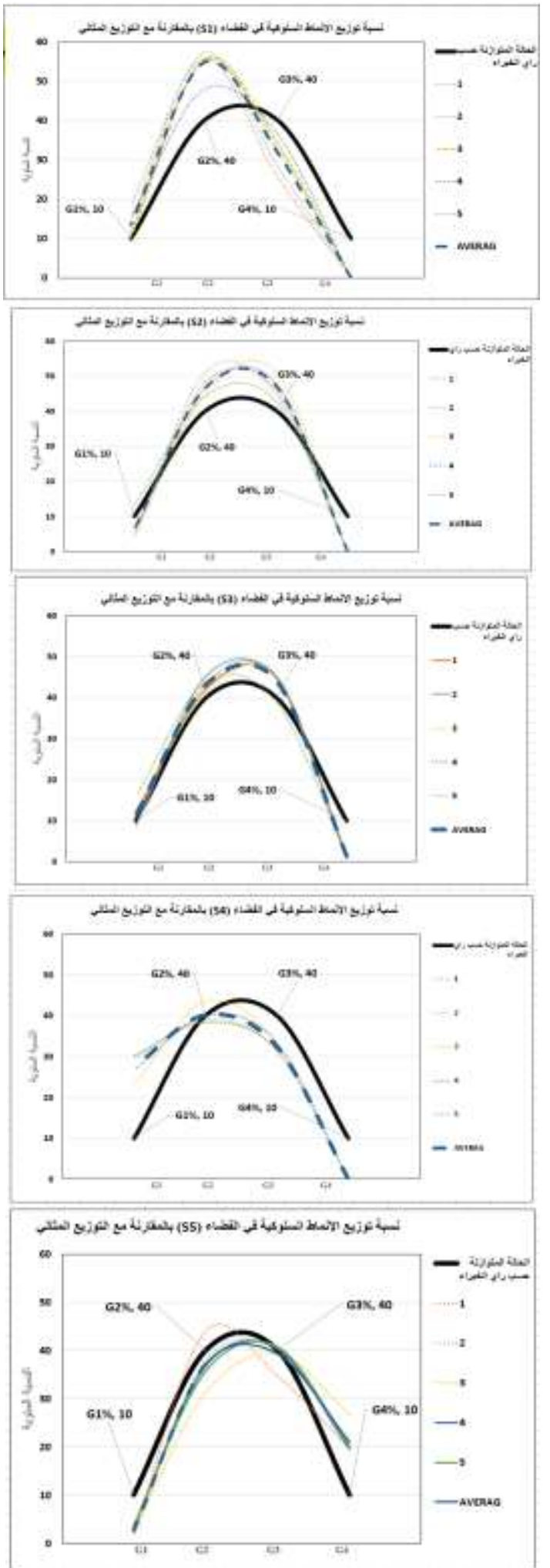

شكل رقم (5):- نسب توزيع الانماط السلوكية في الفضاء المنتخبة

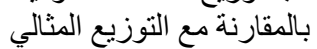




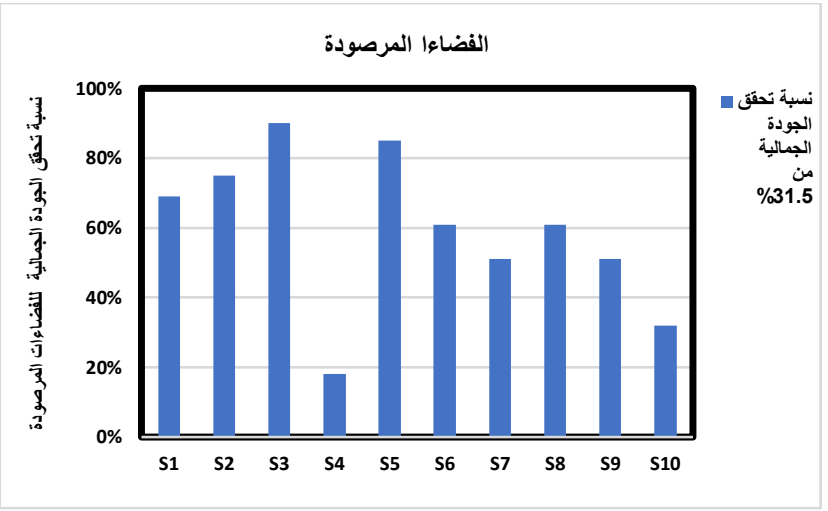

شكل رقم (6):- يوضح نسبة تحقق الجودة الجمالية في الفضاءات

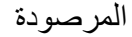

جدول رقم (1):- يوضح ارتباط بيرسون بين الجودة الجمالية ومفرداتها الرئيسية مع الانماط السلوكية السائدة

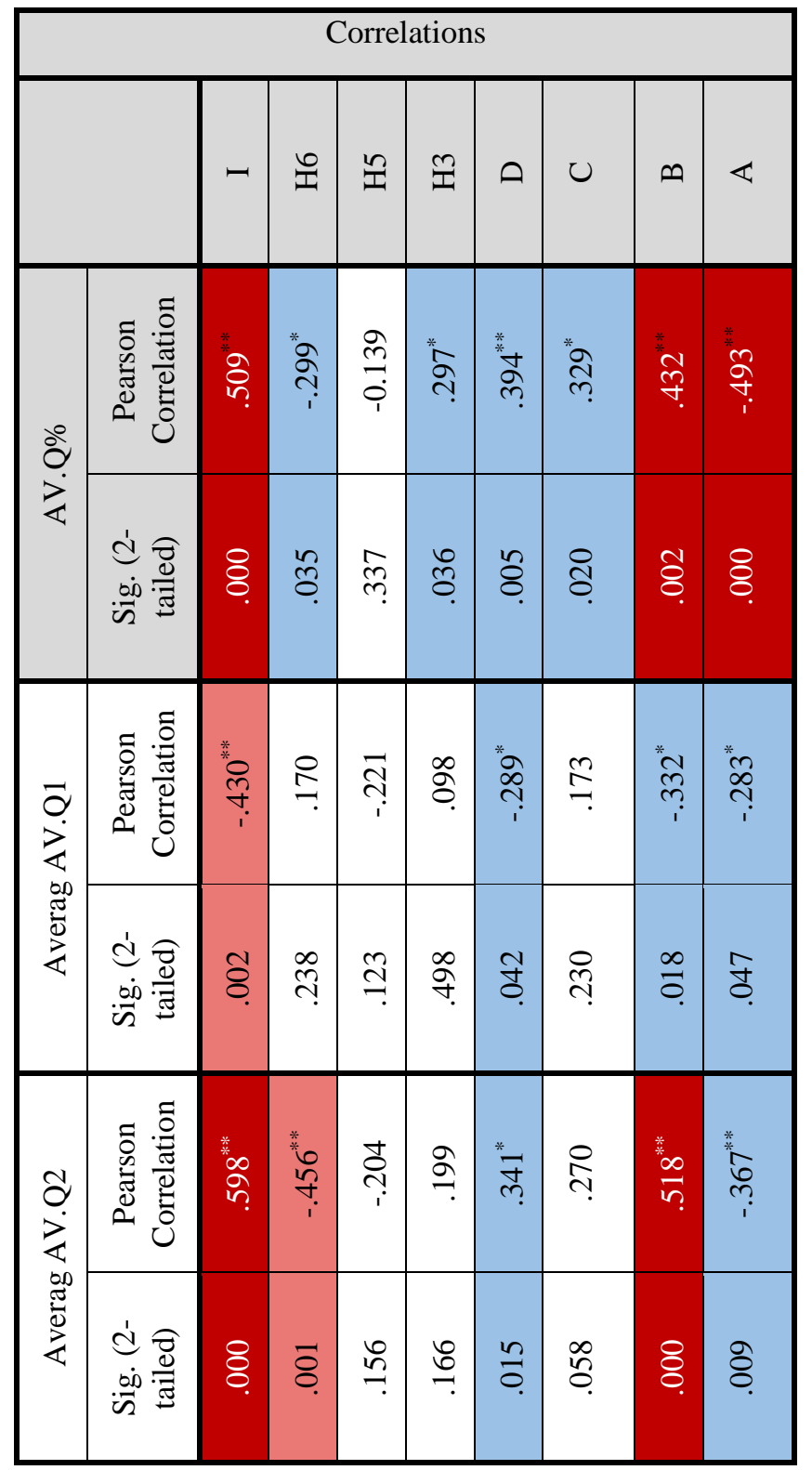

الاستنتاجات

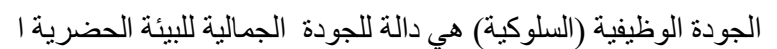

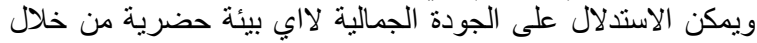

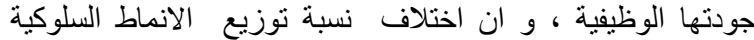

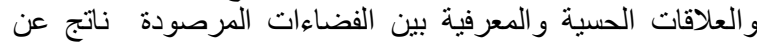
اختلاف الجودة الجمالية للبيئة الحضرية. لينة

النمط السلوكي (D) لايتاثر بجودة البيئة الحضرية وهو نمط سلوك الحئية

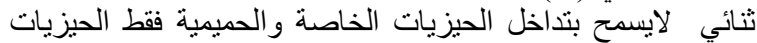

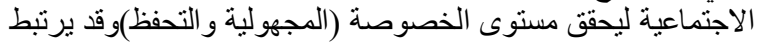

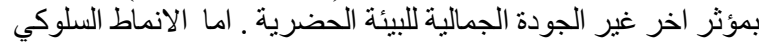

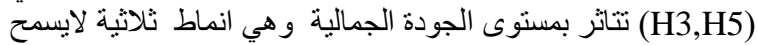

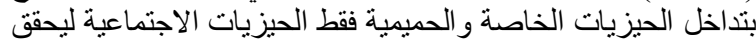

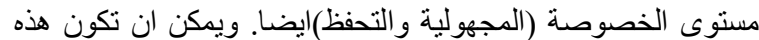

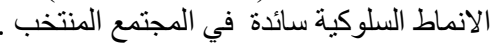

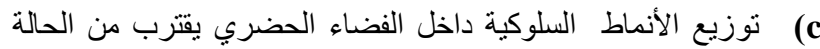

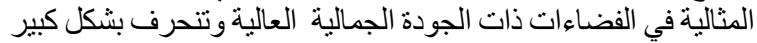
في الفضاءات ذات الجودة الو اطنئة .

الجودة الجمالية للبيئة الحضرية لا ترنبط مع تكرار ظهور العلاقات

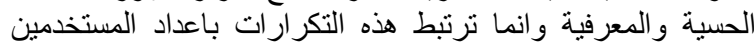

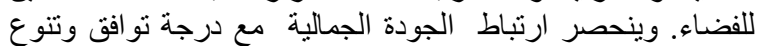

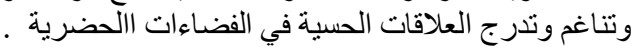

(e

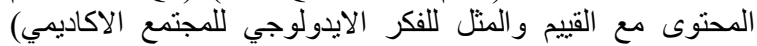

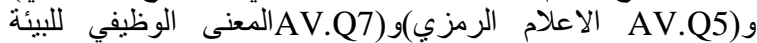
الحضرية ) و(PH.Q2 عناصر التاثيث و الاكسسوارات) و(التلوثي البيئي و الاستدامة (ECO.Q2) هي مؤشر ات لها تاثنير على السلوك وك السائد (D,H3,H5).

المفردات الرئيسة ( AV.Q7 المعنى الوظيفي للبيئة الحضرية ) و (القييم التاريخية الرئ2(AV.Q2)

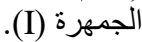

المفردات الرئيسة (القييم التاريخية2AV.Q2) و (AV.Q3 القيبم

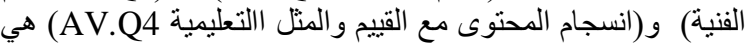

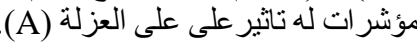

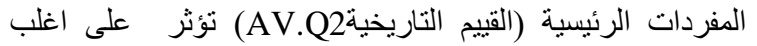
الانماط السلوكية (A,D,H3,H5,I) وطبيعتها. و هنا نعزز ماذهب الرئ اليه

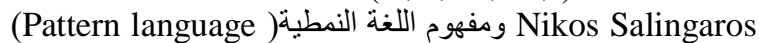
و التي تؤدي الى تكيف السلوك البشري مع البيئة واستجاباتهر. 
جدول رقم (2): - معدل النسب المقترحة من قبل الخبراء والمر اقبة الموقعية اللفضاءات ذات الجودة البيئية العالية (S1,S2,S3)

\begin{tabular}{|c|c|c|c|c|}
\hline 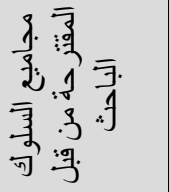 & $\begin{array}{ll}0 \\
0 & \vdots \\
0\end{array}$ & 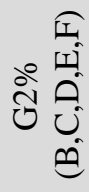 & 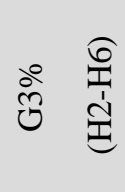 & 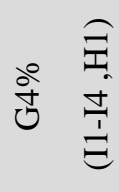 \\
\hline 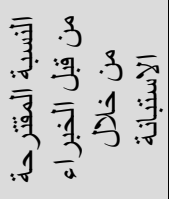 & 10 & 40 & 40 & 10 \\
\hline 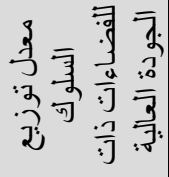 & 9 & 48. & 42 & 1 \\
\hline 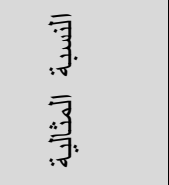 & 9.5 & 44 & 41 & 5.5 \\
\hline
\end{tabular}

\begin{tabular}{|c|c|c|c|c|c|c|c|c|c|}
\hline $\begin{array}{l}2 \\
\dot{2} \\
\dot{<}\end{array}$ & 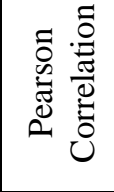 & $\stackrel{\infty}{+}$ & $\tilde{n}$ & $\vec{F}$ & 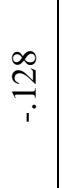 & $\stackrel{m}{\Xi}$ & $\begin{array}{l}\mathfrak{n} \\
\text { ஸे }\end{array}$ & $\stackrel{\infty}{ \pm}$ & $\stackrel{*}{\stackrel{*}{\Xi}}$ \\
\hline$\stackrel{\vec{D}}{\vec{\alpha}}$ & 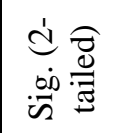 & ?ి & 8 & ธิ & $\underset{\oplus}{\mathbb{N}}$ & $\stackrel{6}{\circ}$ & రి & $\stackrel{\mathcal{Y}}{\leftarrow}$ & రి \\
\hline 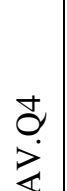 & 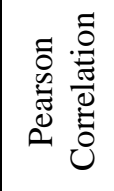 & तิ & $\stackrel{0}{\underset{1}{i}}$ & $\stackrel{n}{?}$ & 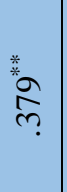 & 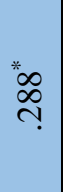 & 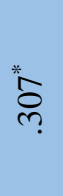 & $\overrightarrow{\widetilde{N}}$ & 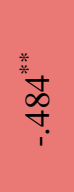 \\
\hline$\vec{z}$ & 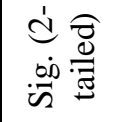 & $\stackrel{\hat{\sigma}}{0}$ & $\vec{m}$ & $\stackrel{ \pm}{-}$ & $\tilde{8}$ & $\stackrel{m}{\sigma}$ & గ్రి & రి & 8 \\
\hline $\begin{array}{l}a \\
a \\
\dot{z} \\
\dot{z}\end{array}$ & 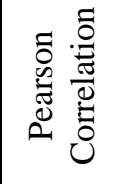 & $\stackrel{*}{\tilde{*}}$ & $\underset{0}{i}$ & 守 & 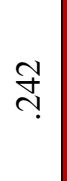 & 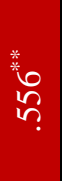 & $\stackrel{\infty}{\infty}$ & 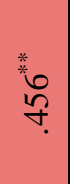 & $\stackrel{8}{7}$ \\
\hline$\vec{Z}$ & 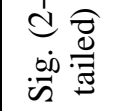 & 8 & $\stackrel{\text { Iq }}{\mathrm{q}}$ & 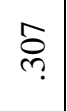 & \&. & ఫి & $\begin{array}{l}n \\
n \\
n\end{array}$ & $\overline{8}$ & $\widehat{\infty}$ \\
\hline $\begin{array}{l}\stackrel{2}{\circ} \\
\stackrel{2}{<}\end{array}$ & 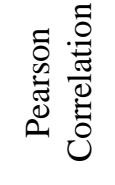 & $\frac{m}{m}$ & $\tilde{w}_{n}^{n}$ & $\stackrel{n}{n}$ & $\underset{0}{0}$ & $\stackrel{8}{\circ}$ & 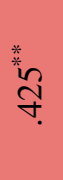 & $\stackrel{\infty}{\dddot{m}}$ & $\underset{i}{\exists}$ \\
\hline $\overrightarrow{4}$ & 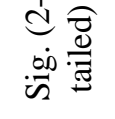 & $\widehat{\widehat{\delta}}$ & ఫి & $\overline{0}$ & $\stackrel{\infty}{\stackrel{\rho}{f} .}$ & $\vec{r}$ & ชิ & ले & ঙิ \\
\hline 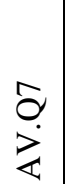 & 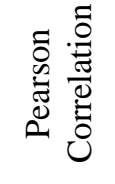 & $\bar{\nabla}$ & $\underset{n}{\tilde{0}}$ & $\underset{i}{8}$ & है & ণิ ઼ิ & กิ & $\frac{0}{\mathfrak{v}}$ & 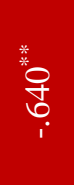 \\
\hline$\vec{z}$ & 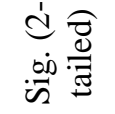 & $\vec{m}$ & $\stackrel{\overbrace{}}{\check{c}}$ & 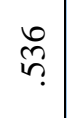 & $\bar{\delta}$ & กิ & ฮิ & ?ี & 8 \\
\hline \multicolumn{10}{|c|}{$\begin{array}{l}\text { **. Correlation is significant at the } \\
0.01 \text { level (2-tailed). }\end{array}$} \\
\hline \multicolumn{7}{|c|}{$\begin{array}{c}\text { *. Correlation is significant at the } \\
0.05 \text { level (2-tailed). }\end{array}$} & 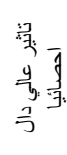 & 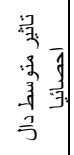 & 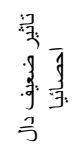 \\
\hline
\end{tabular}




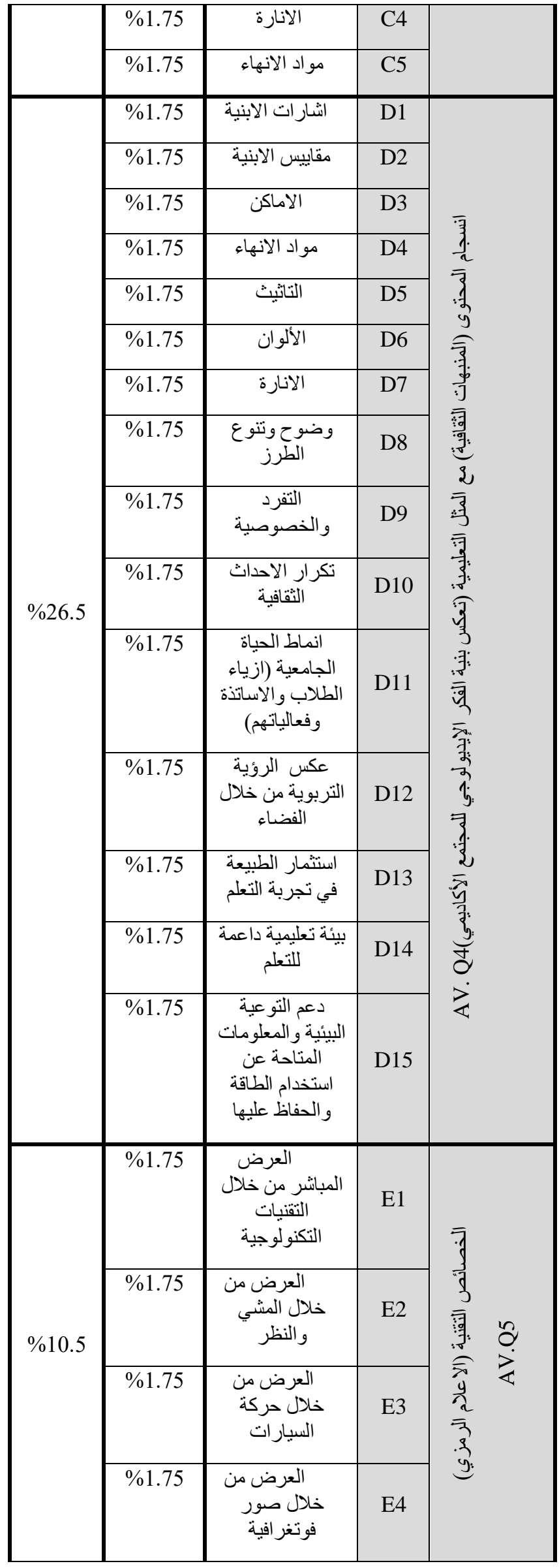

جدول رقم (3):- - الاوزان الترجيحية الافراضية لمؤشرات الجودة

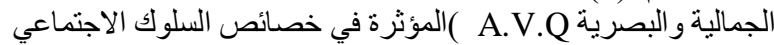

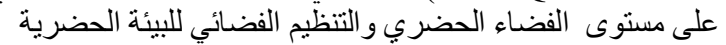

\begin{tabular}{|c|c|c|c|c|}
\hline 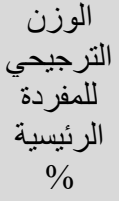 & 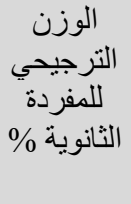 & 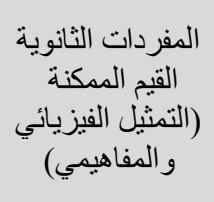 & الرمز & الرئيسية \\
\hline \multirow{12}{*}{$\% 21$} & $\% 1.75$ & اشـار ات الابنية & A1 & \multirow{12}{*}{ 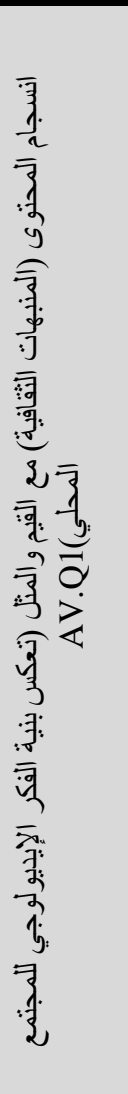 } \\
\hline & $\% 1.75$ & مقاييس الابنية & A2 & \\
\hline & $\% 1.75$ & الاماكن & A3 & \\
\hline & $\% 1.75$ & مو اد الانهاء & A4 & \\
\hline & $\% 1.75$ & التاثيث & A5 & \\
\hline & $\% 1.75$ & الالوان & A6 & \\
\hline & $\% 1.75$ & الانارة & A7 & \\
\hline & $\% 1.75$ & وضوح وتتوع & A8 & \\
\hline & $\% 1.75$ & و الخصوصبة & A9 & \\
\hline & $\% 1.75$ & الجامعية (ازياء الحياة & A10 & \\
\hline & $\% 1.75$ & تعزيز الثقافة & A11 & \\
\hline & $\% 1.75$ & تكر ار الاحداث & A12 & \\
\hline \multirow{5}{*}{$\% 8.75$} & $\% 1.75$ & تاريخية اتروز & B1 & \multirow{5}{*}{ 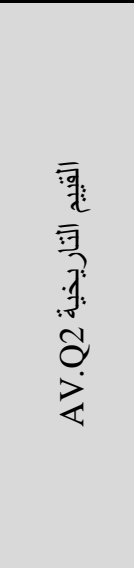 } \\
\hline & $\% 1.75$ & استخدام المواد المحلية، & B2 & \\
\hline & $\% 1.75$ & توظيف الانقليدية، & B3 & \\
\hline & $\% 1.75$ & استخدام الزخرفة & B4 & \\
\hline & $\% 1.75$ & تعزيز هوية الحرم & B5 & \\
\hline \multirow{3}{*}{$\% 8.75$} & $\% 1.75$ & لختق الدراما النباتات & $\mathrm{C} 1$ & \multirow{3}{*}{ 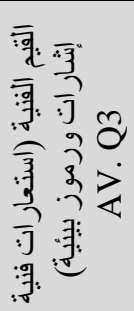 } \\
\hline & $\% 1.75$ & الطبو استخراميا او & $\mathrm{C} 2$ & \\
\hline & $\% 1.75$ & الالوان & $\mathrm{C} 3$ & \\
\hline
\end{tabular}


جدول رقم (4): - المقومات الثقافية للحرم الجامعي في مر احل التطور الخمسة.

\begin{tabular}{|c|c|c|}
\hline افرزتها الدراتوات الحضر التاريخية الحضية على مستية التي & الحضر مقاتة & الجاريخياً \\
\hline 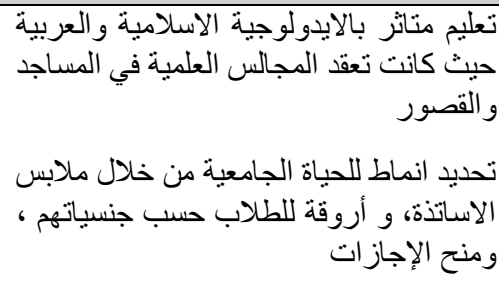 & ثقافية & \multirow{2}{*}{ 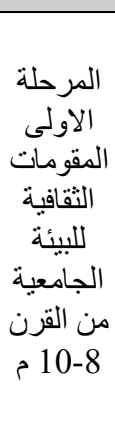 } \\
\hline 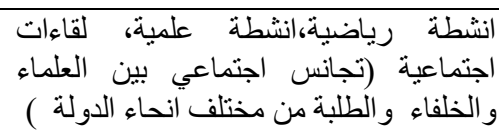 & اجتماعية & \\
\hline 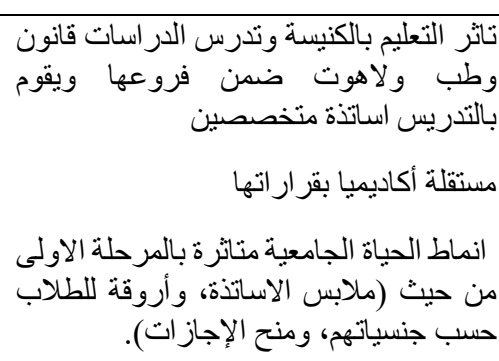 & ثقافية & \multirow[t]{2}{*}{ 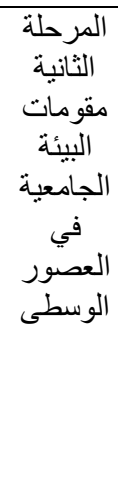 } \\
\hline 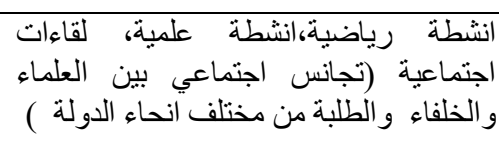 & اجتماعية & \\
\hline 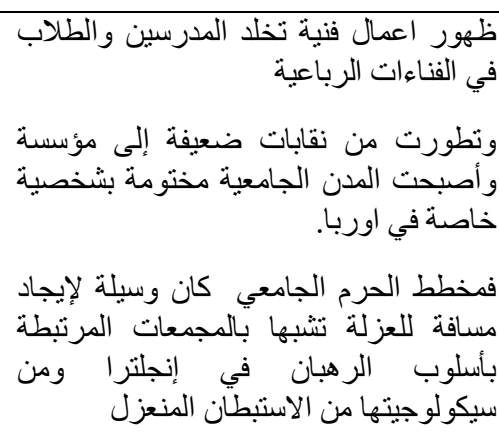 & ثقافية & \multirow[t]{2}{*}{ 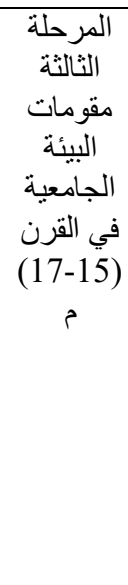 } \\
\hline 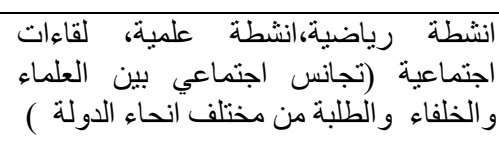 & اجتماعية & \\
\hline 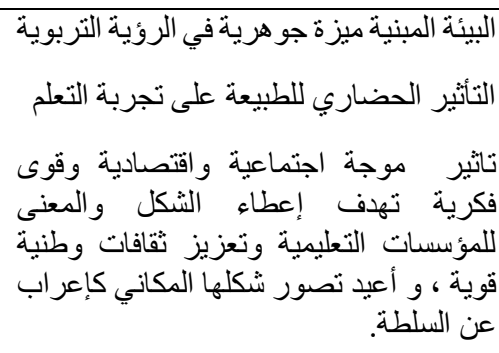 & ثقافية & 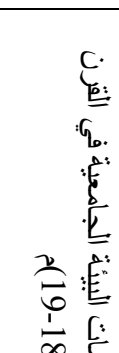 \\
\hline 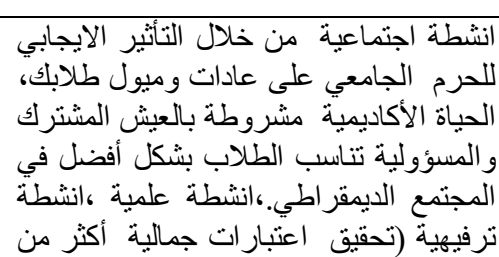 & اجتماعية & E. \\
\hline
\end{tabular}

\begin{tabular}{|c|c|c|c|c|}
\hline & $\% 1.75$ & 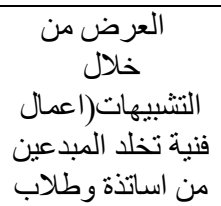 & E5 & \\
\hline & $\% 1.75$ & 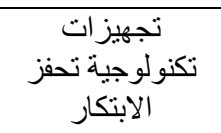 & E6 & \\
\hline \multirow{6}{*}{$\% 10.5$} & $\% 1.75$ & المشهـ او الرؤية & F1 & \multirow{6}{*}{ 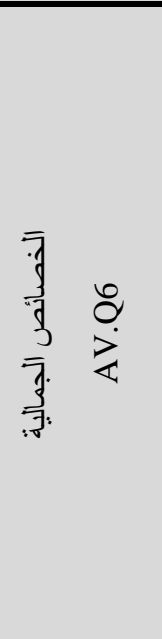 } \\
\hline & $\% 1.75$ & المشهـ المنظوري & $\mathrm{F} 2$ & \\
\hline & $\% 1.75$ & التجاور و التتاقض & F3 & \\
\hline & $\% 1.75$ & تنوع العناصر & F4 & \\
\hline & $\% 1.75$ & 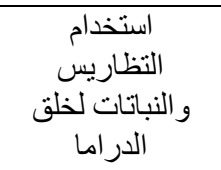 & F5 & \\
\hline & $\% 1.75$ & فيزيائية لخلق الدامر & F6 & \\
\hline \multirow{9}{*}{$\% 14$} & $\% 1.75$ & تنوع الفعاليات & G1 & \multirow{9}{*}{$\begin{array}{l}\text { الوظيفية للبيئة } \\
\text { الحضرية } \\
\text { AV.Q7 }\end{array}$} \\
\hline & $\% 1.75$ & النظافة & $\mathrm{G} 2$ & \\
\hline & $\% 1.75$ & الترفيه & G3 & \\
\hline & $\% 1.75$ & الامن & $\mathrm{G} 4$ & \\
\hline & $\% 1.75$ & توفير خدمات & G5 & \\
\hline & $\% 1.75$ & المستخدمين من & G6 & \\
\hline & $\% 1.75$ & 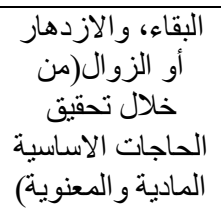 & G7 & \\
\hline & $\% 1.75$ & 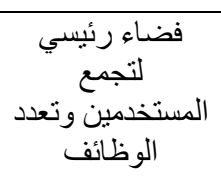 & G8 & \\
\hline & $\% 100$ & نسبة الفقرات من & & \\
\hline
\end{tabular}




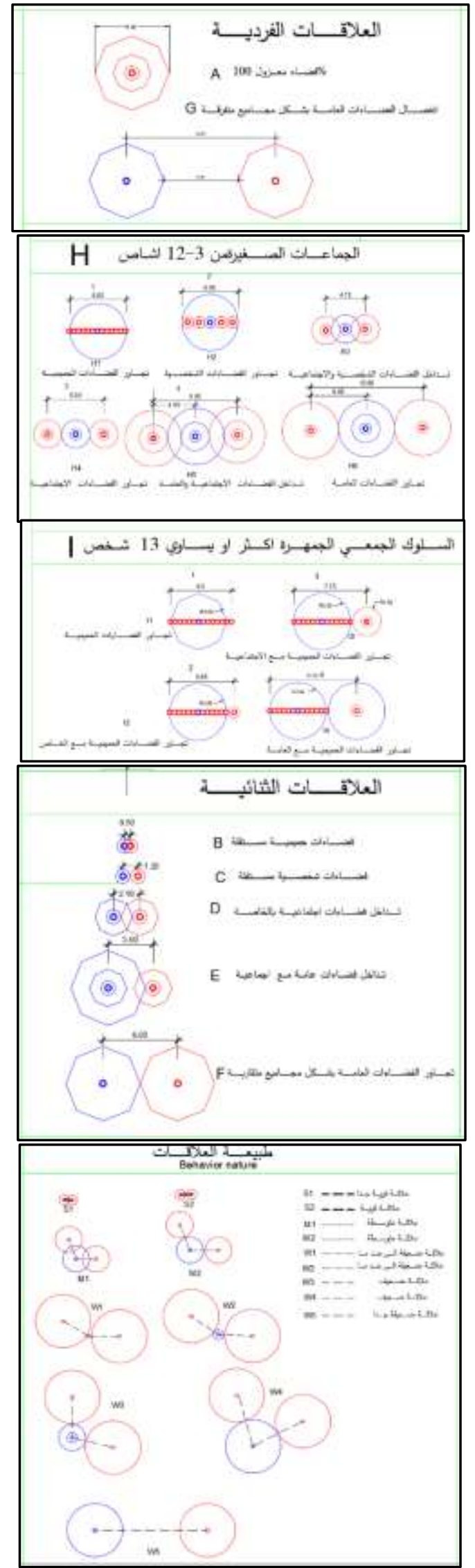

شكل رقم (8): - مؤشر ات انماطوطييعة السلوك

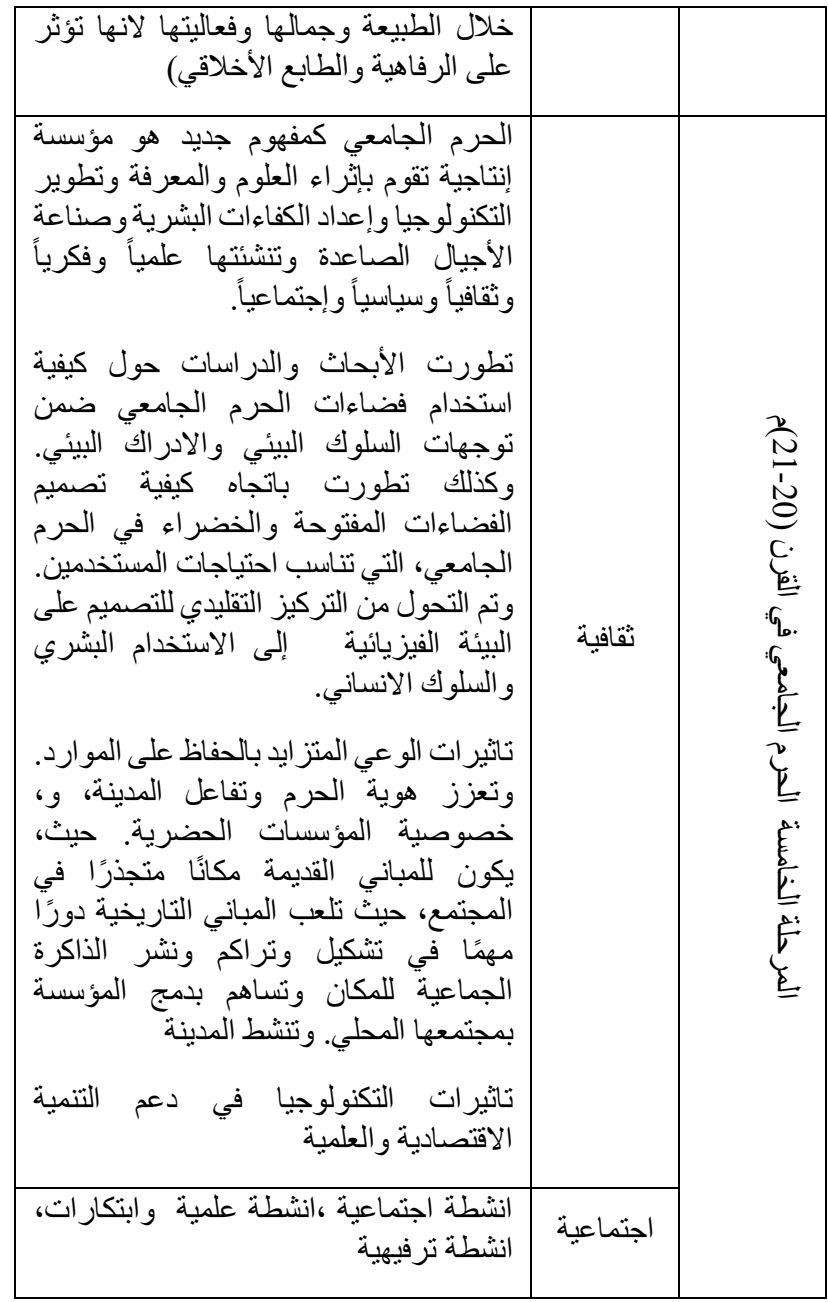


جدول رقم (7) :-يوضح درجة التوافق و التدرج لتوزيع العلاقات الحسية و المعرفية في العينات المنتخبة

\begin{tabular}{|c|c|c|c|c|c|c|c|c|}
\hline \multirow[b]{2}{*}{23} & \multicolumn{7}{|c|}{ G } & \multirow{2}{*}{ top } \\
\hline & II & II & $\mathrm{IB}$ & 14 & I5 & III & II & \\
\hline SI & 64.5 & Inयार & mings & 127.225 & $28 \mathrm{ins}$ & 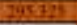 & DE4 475 & ب \\
\hline s2 & 215 & 10775 & 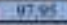 & 57073 & 1. 12575 & 1363 & प्राIII & 4,4 \\
\hline So & 11.65 & 3.78 & 711 & 35.4 & is & 114.35 & 202 & 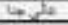 \\
\hline 54 & 22.55 & $11 \mathrm{aS}$ & 505 & 55 & 0,623 & 1113 & 268029 & 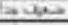 \\
\hline 55 & 1003 & 5115 & 381 & 3003 & min & (1513) & ifing:4 & $-y_{0}$ \\
\hline 5 & 28 & $24 !$ & 218.68 & 6095 & 202235 & 26035 & $30 \%$ & $x^{2}$ \\
\hline 57 & 74 & 37 & 130 & 609 & DQTS & 1005 & 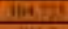 & +6 \\
\hline$\$$ & 18.2 & 96 & $1+56$ & 457 & 1367 & $16+3$ & +1113 & $=$ \\
\hline Q & 18 & ge & 35 & $H 3$ & 329 & 4.13 & $1+1825$ & $6+2$ \\
\hline $\sin$ & Ali & 2055 & Drass & novith & 100215 & $187,1 \times 25$ & 445 & $-\infty$ \\
\hline$\left(\begin{array}{c}(1000)>-14 \\
4+22\end{array}\right)$ & $\begin{array}{l}301 \\
1000 \\
\end{array}$ & $\begin{array}{r}-1001 \\
6250 \\
120\end{array}$ & (a) & $(25-1)$ & & & & \\
\hline
\end{tabular}

المصادر

[1] [ابو العز ام، عبد الغني،"معجم الغني الزاهر "، مؤســـــة الغني للنشـر

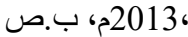

[2] بطرس ،د.بطرس حافظ "تعديل وبناءالسـلوك"،دار المسـيرة للنشـر

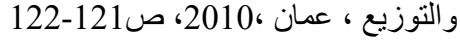

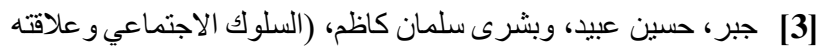

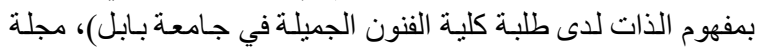

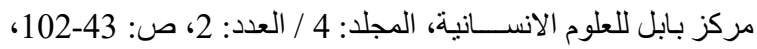
، 2014

[4] حميد|، د.فارس شكري،" المقاومة الثقافية في البيئة الحضرية: در اسـة

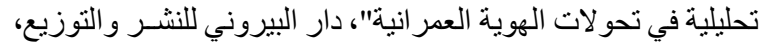

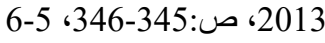

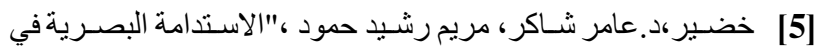

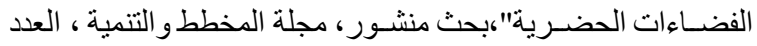
32 32، ص: 32-1، 2015

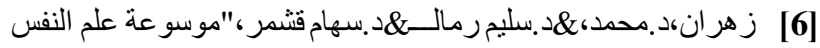

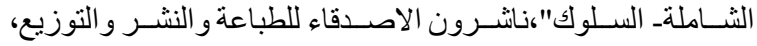

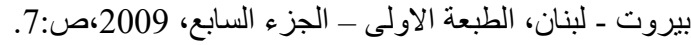

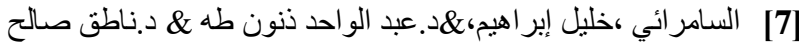

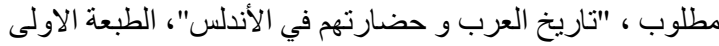

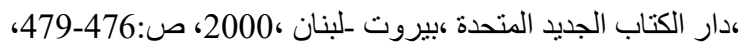

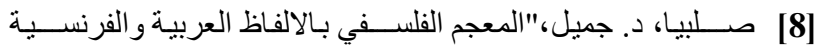

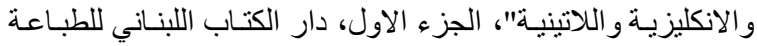

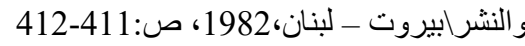

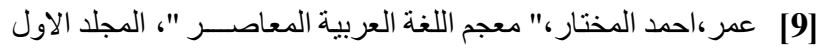

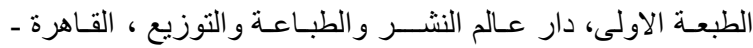

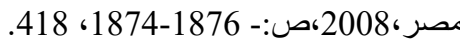

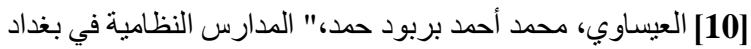

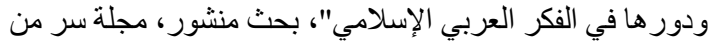

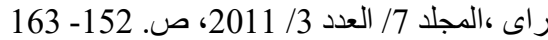

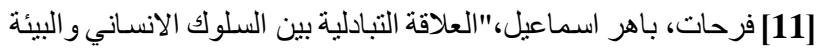

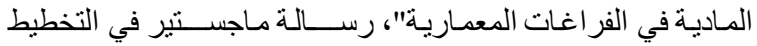

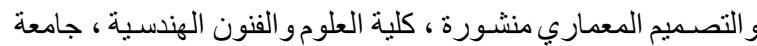

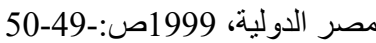

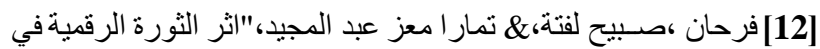
التنظيم الفضـائي للمحلة السـكنية"،مجلة المخطط و التتمية ، العدد 35 ، 55-84:صنافي 2017،

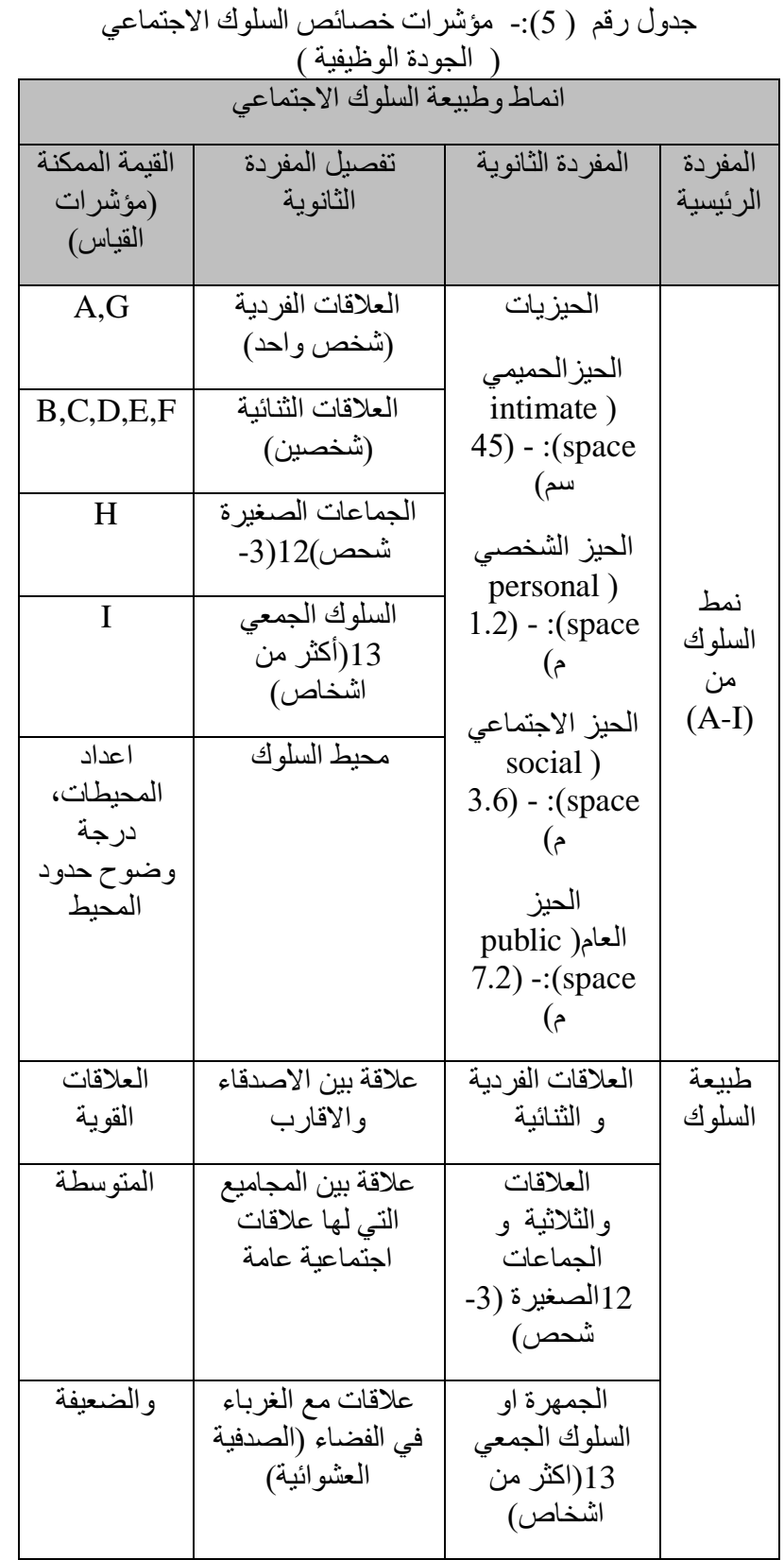

جدول رقم (6) :-يوضح تكرار ظهور النمط السلوكي ودرجة قوة العلاقات

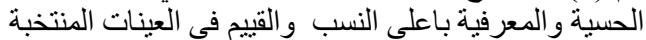

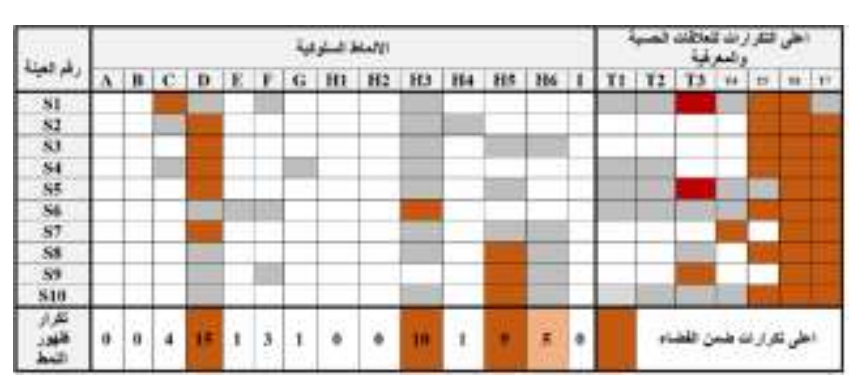


Considerations." National Geographical Journal of India 54.4 (2011): 73-82.

[27] Gibson, james J. the Environment as Source of Stimulation!In The Senses Considered as Perceptual Systems. Boston K Houghton Mifflin, 1966, p: -7

[28] Granovetter, Mark S. "The strength of weak ties." Social networks. 1977, p: - 347-367.

[29] Hanafi, Israa, et al. "Human Social Behavior in Public Urban Spaces: Towards Higher Quality Cities." Spaces \& Flows: An International Journal of Urban \& Extra Urban Studies ,2013, (3, 2)., P: - 29,

[30]Harry, Heft," Ecological Psychology in Context: James Gibson, Roger Barker, and the Legacy of William,2001.

[31] Hourakhsh Ahmad, \& Yousif Hussien Suleiman Nia," Aesthetics of Space Organization: Lessons from Traditional European Cities", Contemporary Urban Affairs, 2018, Volume 2, Number 1, p: - 70

[32] Jacobs, Jane," THE DEATH AND LIFE OF GREAT AMERICAN CITIES", VINTAGE BOOKS A Division of \&ndo111 HOllse, NEW YORK, 1961, p: 32-35

[33]James J.F. Forest and Philip G. Altbach (eds.), "International Handbook of Higher Education", 159205. C 2007Springer

[34]Kim, Young Jae," Camillo Sitte's Urban Design Language and its Influence upon Adolf Loos's Raumplan", ARCHITECTURAL RESEARCH, Vol. 17, No. 1(March 2015). pp. 2-4,

[35]Lang, John, (1987); " Creating Architectural Theory; The Role of the Behavioral Sciences in The Environmental Designs ", Von Nostrand Reinhold Company, New York. P: -93,90-91,84,78-79,146147,148,147,113,11,114-115.

[36]Larice, Michael, and Elizabeth Macdonald" THE URBAN DESIGN READER", Second edition, Urban Reader Series, USA, 2013, p: -273-276,118-119

[37] Habib, Farah, \& Sayyed Mohammad Khosro Sahhaf, " Christian Norberg-Schulz and the Existential Space ", International Journal of Architecture and Urban Development,2012, (1, 3,),

[38]Lynch, K., (1960); " The image of The City ", The MIT Press.

[39]Namazian, $\mathrm{PhD}$ Ali, and Armin Mehdipour. "Psychological Demands of the Built Environment, Privacy, Personal Space and Territory in Architecture." International Journal of Psychology and Behavioral Sciences 3.4 (2013): 109-113

[40] Nichol, Janet, and Man Sing Wong. "Modeling urban environmental quality in a tropical city." Landscape and urban planning 73.1 (2005): 49-58

[41] Rapoport, A., (1977), "Human Aspects of Urban Form), Pergamon Press, U.K., p: - 109, 8-12

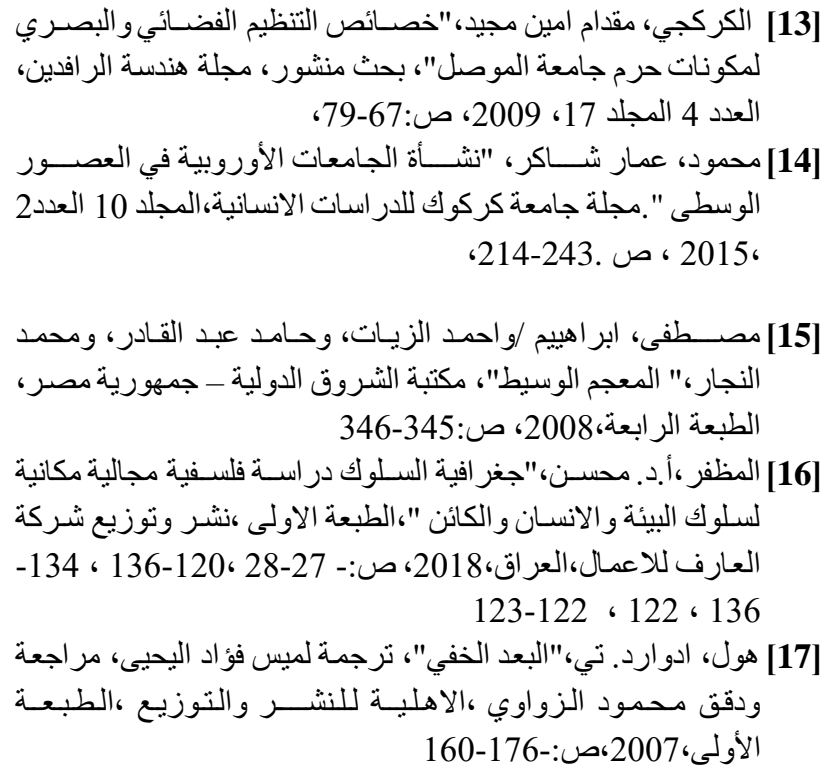

[18]Allen, Thomas J. "Managing the flow of technology: Technology transfer and the dissemination of technological information within the R\&D organization." MIT Press Books 1 (1984), p: -182206.

[19]Ar-Rifai, T. 1988.TheNew University Environment.Ph.D. Thesis Submitted to the University of Pennsylvania, USA.

[20]Aydin, Dicle, and Ummugulsum Ter. "OUTDOOR SPACE QUALITY: CASE STUDY OF A UNIVERSITY CAMPUS PLAZA." Archnet-Ijar 2.3 (2008).p:-189,190

[21]Barker, Roger Garlock. "Ecological psychology: Concepts and methods for studying the environment of human behavior." (1968), P: - 30-48,

[22] Bratman, Gregory N., J. Paul Hamilton, and Gretchen C. Daily. "The impacts of nature experience on human cognitive function and mental health." Annals of the New York Academy of Sciences 1249.1 (2012): 118136.

[23]Coulson , Jonathan ,\& Paul Roberts,\& Isabelle Taylor ,"University Trends: Contemporary Campus Design", Routledge,New Yourk ,NY ,2second edition , 2018 ,P:10-13

[24]Coulson, Jonathan, Paul Roberts, and Isabelle Taylor," University planning and architecture: The search for perfection", Routledge Taylor \& Francis Group London and New York, 2nd Edition, 2015. P: $-7-30$

[25]Cullen, Gordon. "The Concise Townscape, 1971.", Elsevier -Architectural press, (1977), reprinted 2006,13-195

[26]Fakhruddin, Subia Aftab, and Mohammad Firoz Khan. "Quality of Urban Environment: Some Theoretical and Methodological 
[42] Rapoport, Amos, (1981), "Urban Design and Human Systems: On Way of Relating Building to Urban Fabric), University of Wisconsin-Milwaukee, USA.p: -161-184

[43] Rasoulpour, Hazhir and Farzin Charehjoo. 2017. "The Effect of the Built Environment on the Human Psyche Promote Relaxation.” Architecture Research 7(1):1623. p: $-18,17-18$

[44] Robinson, Sarah\& Juhani Pallasmaa," MIND IN ARCHITECTURE NEUROSCIENCE, EMBODIMENT, AND THE FUTURE OF DESIGN ", MIT Press Cambridge, London, England,2015, p: 4 ,3-7,33

[45] Salingaros, Nikos," A Theory of Architecture",Nikos A. Salingaros,2016 ,p:- chpter.1,2,3

[46]Sullivan, Gail M., and Anthony R. Artino Jr. "Analyzing and interpreting data from Likert-type scales." Journal of graduate medical education 5.4 (2013): 541-542.

[47] Yang, Huan. Campus landscape space planning and design using QFD. Diss. Virginia Tech, 2007.p: -2-7

[48] Yuki, Masaki, et. al, (Social ecology moderates the association between self-esteem and happiness), Journal of Experimental Social Psychology, 49,741746,2013

[49] Yerli, Ozgur, and Sinem Ozdede. "Design Process of a Campus Plan: A Case Study of Duzce University Konuralp Campus.", Journal of Engineering Research

[50] and Application, Vol. 7, Issue 4, (Part -1) April 2017, pp.50-59

[51]Hines, Ryan K.," Review of Literature: Potential Benefits of Urban Nature Exposure and Stream Corridor Based Recreation ", A Student Journal in Recreation, Parks, and Tourism Studies, Volume 15, Issue 1, pages 33-46, 2017 p: -35,

[52]Hillier, Bill, and Julienne Hanson. The social logic of space. Cambridge university press, 1988. ,P: -6-7

[53]Brown, Nina. "Edward T. Hall: Proxemic Theory, 1966." Center for Spatially Integrated Social Science. University of California, Santa Barbara. http://www. csiss. org/classics/content/13 Read18 (2001): 2007., P: -7 ,

[54] Hillier, Bill," Space is the machine." Cambridge university press, Cambridge, 1996, p: -196-197 


\title{
The Cultural Constituents of the urban environment; the impact on the patterns and nature behavior (University space as a model)
}

\author{
Ameera Jaleel Ahmed 1, Saba Jabbar Neima ${ }^{2, *}$ \\ ${ }^{1}$ Department of Architecture Engineering, Faculty of Engineering, University of Baghdad, Baghdad, Iraq, ameera_jaleel@yahoo.com \\ ${ }_{2}^{2}$ Department of Architecture Engineering, Faculty of Engineering, University of Baghdad, Baghdad, Iraq, dr.saba_alkhafaji@yahoo.com \\ * corresponding author: Ameera Jaleel Ahmed,ameera_jaleel@yahoo.com \\ Published online: 31 March 2021
}

Abstract-Human's relationship with the environment is strong and mutually beneficial, with the development of this relationship, a person develops and increases his awareness. The urban environment is a natural, physical, social and cultural milieu that a human lives in it, and get from him the life Constituents. As well as it is a product of human interaction with it, so the urban environment represents what has an impact on human behavior. It effects on human physiology and psychology then represented the relationship conceptually, socially, and physically. the Cultural Constituents of the urban environment plays a critical and essential role in user behavior, because they are part of the project they must be included in making the design decision as well as in treatment of urban spaces. on the other side, the comprehensive behavioral studies are still few in this field, especially those studies that are based on ecological behavioral trend and through observing of behavior in the urban environment . The current study seeks to draw out a theoretical model for developing ecological behavior measures, to evaluate the role of Cultural Constituents in determining patterns and nature of human behavior through the experimental approach. Through the previous literature has been identified the main research problem is represented ( There is a lack of knowledge in the distribution of behavioral patterns in urban environments that have a high aesthetic quality, also there are few objective measures that can be used as an indicator to evaluate the aesthetic quality of the urban environment before its development and presenting urban designs in urban space and special organization ).According to the research problem, the goals and hypothesis of the research were determined, and an inductive experimental approach was defined theoretical and practical axes, also the research samples were identified (ten urban spaces in University of Babylon) were observing during (20182019),furthermore survey questionnaire sent to the experts In architecture, urban design and psychology field .Finally, the results were analyzed and the research found that aesthetic quality plays an important and major role in determining patterns and nature of behavior.

Keywords-“" Cultural Constituents", "aesthetic quality of urban environment "," Functional quality of urban environment"," behavioral patterns"," behavioral nature " 